\title{
A meta-analysis of genome-wide data from five European isolates reveals an association of COL22A1, SYT1, and GABRR2 with serum creatinine level
}

Cristian Pattaro $^{1 *}$, Alessandro De Grandi ${ }^{1}$, Veronique Vitart ${ }^{2}$, Caroline Hayward ${ }^{2}$, Andre Franke ${ }^{3}$, Yurii S Aulchenko ${ }^{4}$, Asa Johansson ${ }^{5}$, Sarah H Wild ${ }^{6}$, Scott A Melville', Aaron Isaacs ${ }^{4}$, Ozren Polasek ${ }^{7,8}$, David Ellinghaus ${ }^{3}$, Ivana Kolcic ${ }^{7}$, Ute Nöthlings ${ }^{9,10}$, Lina Zgaga ${ }^{7}$, Tatijana Zemunik ${ }^{11}$, Carsten Gnewuch ${ }^{12}$, Stefan Schreiber ${ }^{3}$, Susan Campbell ${ }^{2}$, Nick Hastie ${ }^{2}$, Mladen Boban ${ }^{11}$, Thomas Meitinger ${ }^{13,14}$, Ben A Oostra ${ }^{4}$, Peter Riegler ${ }^{15}$, Cosetta Minelli ${ }^{1}$, Alan F Wright ${ }^{2}$, Harry Campbell ${ }^{6}$, Cornelia M van Duijn ${ }^{4}$, Ulf Gyllensten ${ }^{5}$, James F Wilson ${ }^{6}$, Michael Krawczak ${ }^{9,16}$, Igor Rudan ${ }^{6,8,11}$, Peter P Pramstaller ${ }^{1,17,18^{*}}$, the EUROSPAN consortium

\begin{abstract}
Background: Serum creatinine $\left(S_{C R}\right)$ is the most important biomarker for a quick and non-invasive assessment of kidney function in population-based surveys. A substantial proportion of the inter-individual variability in $S_{C R}$ level is explicable by genetic factors.
\end{abstract}

Methods: We performed a meta-analysis of genome-wide association studies of $S_{C R}$ undertaken in five population isolates ('discovery cohorts'), all of which are part of the European Special Population Network (EUROSPAN) project. Genes showing the strongest evidence for an association with $S_{C R}$ (candidate loci) were replicated in two additional population-based samples ('replication cohorts').

Results: After the discovery meta-analysis, 29 loci were selected for replication. Association between $S_{C R}$ level and polymorphisms in the collagen type XXII alpha 1 (COL22A1) gene, on chromosome 8, and in the synaptotagmin-1 (SYT1) gene, on chromosome 12 , were successfully replicated in the replication cohorts ( $p$ value $=1.0 \times 10^{-6}$ and $1.7 \times 10^{-4}$, respectively). Evidence of association was also found for polymorphisms in a locus including the gamma-aminobutyric acid receptor rho-2 (GABRR2) gene and the ubiquitin-conjugating enzyme E2-J1 (UBE2J1) gene (replication $\mathrm{p}$ value $=3.6 \times 10^{-3}$ ). Previously reported findings, associating glomerular filtration rate with SNPS in the uromodulin (UMOD) gene and in the schroom family member 3 (SCHROOM3) gene were also replicated.

Conclusions: While confirming earlier results, our study provides new insights in the understanding of the genetic basis of serum creatinine regulatory processes. In particular, the association with the genes SYT1 and GABRR2 corroborate previous findings that highlighted a possible role of the neurotransmitters $G_{A B A}$ receptors in the regulation of the glomerular basement membrane and a possible interaction between $G_{A B A}$ receptors and synaptotagmin-l at the podocyte level.

\footnotetext{
* Correspondence: cristian.pattaro@eurac.edu; peter.pramstaller@eurac.edu ${ }^{1}$ Institute of Genetic Medicine, European Academy Bozen/Bolzano (EURAC), Bolzano, Italy - Affiliated Institute of the University Lübeck, Lübeck, Germany
} 


\section{Background}

In epidemiological population-based surveys, serum creatinine $\left(\mathrm{S}_{\mathrm{CR}}\right)$ represents the most important biomarker for a quick and non-invasive assessment of kidney function, allowing estimation of the glomerular filtration rate (GFR) [1]. At the same time, an increased $S_{C R}$ level has also been recognized as a risk factor for adverse outcomes in patients hospitalized for cardiac surgery or heart failure [2]. A substantial proportion of the interindividual variability in $\mathrm{S}_{\mathrm{CR}}$ level is explicable by genetic factors. Twin [3] and pedigree-based studies [4-7] yielded heritability estimates ranging from 0.19 to 0.53 , with higher values observed in subjects not treated for hypertension [4]. A large number of genetic loci have emerged from genome-wide linkage analyses as being related to variation in $\mathrm{S}_{\mathrm{CR}}$ level or in $\mathrm{S}_{\mathrm{CR}}$-based estimates of both GFR and creatinine clearance [4-15]. Focusing upon quantitative renal phenotypes, a recent GWA study [16] and a subsequent replication study [17] identified variants in the 5,10-methenyltetrahydrofolate synthetase (MTHFS) gene to be associated with chronic kidney disease (CKD; defined as GFR $<60 \mathrm{ml} /$ $\min / 1.73 \mathrm{~m}^{2}$ ). More recently, variants in the uromodulin $(U M O D)$ gene have been shown to be associated with GFR and CKD independent of age, sex, hypertension, and diabetic status [18]. In the same study, SNPs in the schroom family member 3 (SCHROOM3) gene, the glycine amidinotransferase (GATM)-spermatogenesis associated 5-like 1 (SPATA5L1) locus, and in the jagged 1 (JAG1) gene were also found to be associated with GFR [18].

We have reported linkage between $\mathrm{S}_{\mathrm{CR}}$ level and a region at 22q13 containing the myosin heavy chain 9 non-muscle (MYH9) gene [4], a locus that had been associated with non-diabetic end-stage renal disease (ESRD) [19,20] and glomerulosclerosis [21] before. This linkage was detected in families from three isolated European populations participating in the European Special Population Research Network (EUROSPAN). Here, we have performed a genome-wide association analysis of $\mathrm{S}_{\mathrm{CR}}$ level combining data from all five EUROSPAN populations, with $\mathrm{S}_{\mathrm{CR}}$ re-measured using an enzymatic method in one and the same central laboratory. We have performed population-specific GWA studies and subjected the results to an inverse-variance, fixed effects meta-analysis. Selected candidate regions were then tested in two additional, population-based samples from Europe.

\section{Methods}

\section{Study samples}

For all EUROSPAN and replication studies, written informed consent was obtained from all participants and all protocols were approved by the institutional ethical review committees of the participating centres.

\section{Eurospan}

The EUROSPAN project http://homepages.ed.ac.uk/ s0565445/index.html was initiated in 2006 and involves five population isolates from Italy, Croatia, Scotland, Sweden, and the Netherlands. The project aims at assessing the genetic structure of European isolates and at identifying genes underlying common traits, taking advantage of the genetic and environmental homogeneity that usually characterizes population isolates. In the current context, according to Neel [22], with population isolates we mean "secondary isolates", i.e. groups that, for some reasons, detached or were detached from larger populations. In particular, EUROSPAN cohorts were derived from small population samples which have grown slowly, with little recruitment from outside the groups.

The ERF study is a family-based project including over 3000 participants that originated from 22 couples living in the Rucphen region of the Netherlands in the $19^{\text {th }}$ century [23-25]. All descendants of these people were invited to visit a clinical research center in the region, where they were examined in person and where blood was taken after fasting. Height and weight were measured for each participant. All participants filled out a questionnaire on risk factors.

The MICROS study is part of the genomic health care program 'GenNova' and was carried out in three villages of the Val Venosta, South Tyrol (Italy), in 2001-2003. It comprised members of the populations of Stelvio, Vallelunga and Martello. A detailed description of the MICROS study can be found elsewhere [26]. Briefly, study participants were volunteers from three isolated villages located in the Italian Alps, in a German-speaking region bordering upon Austria and Switzerland. Owing to geographical, historical and political reasons, the entire region experienced a prolonged period of isolation from surrounding populations. Information on the participants' health status was collected through a standardized questionnaire. Laboratory data were obtained from standard blood analyses. Genotyping was performed on $>1400$ participants, with 1334 of them suitable for analysis after data cleaning.

The Northern Swedish Population Health Study (NSPHS) is a family-based study including a comprehensive health assessment and the collection of data on family structure, lifestyle, diet, medical history and of samples for laboratory analyses $[27,28]$. Participants came from the northern part of the Swedish mountain region (County of Norrbotten, Parish of Karesuando). Historic population accounts show that little migration 
or population changes have occurred in this area over the last 200 years.

The Orkney Complex Disease Study (ORCADES) is an ongoing, family-based and cross-sectional study in the isolated Scottish archipelago of Orkney [29]. Genetic diversity in this population is reduced in comparison to Mainland Scotland, consistent with high levels of historical endogamy. Participants were aged 18-100 years and came from a subgroup of ten islands. Fasting blood samples were collected and over 200 health-related phenotypes and environmental exposures were measured in each individual.

The Vis study includes 986 unselected Croatians, aged 18-93 years, who were recruited during 2003 and 2004 from the villages of Vis and Komiza on the Dalmatian island of Vis [30,31]. The settlements on Vis island have a unique history and remained isolated from other villages and the outside world for centuries. Participants were phenotyped for 450 disease-related quantitative traits. Biochemical and physiological measurements were performed, detailed genealogies reconstructed, questionnaires on lifestyle and environmental exposures collected, and blood samples and lymphocytes extracted and stored for further analyses.

All DNA samples were genotyped on Illumina Infinium HumanHap300 v2 SNP bead microarrays according to the manufacturer's instructions, except for samples from Vis for which version 1 was used (the Vis samples had 311,398 SNPs genotyped in common with the other populations).

For all five studies, serum or plasma creatinine was measured at the Institute for Clinical Chemistry and
Laboratory Medicine, Regensburg University Medical Center, Germany, using an enzymatic photometric assay on an ADVIA1650 clinical chemistry analyzer (Siemens Healthcare Diagnostics GmbH, Eschborn, Germany) [32]. The number of individuals with available creatinine, sex, and age information is reported for each study in Table 1.

\section{Replication Cohorts}

Data on German healthy control individuals were obtained from the popgen biobank [33]. Genotyping constituted an essential part of the GWAS initiative of the German National Genome Research Network (NGFN) and was performed at an Affymetrix service facility (South San Francisco, CA, USA) using the Affymetrix Genome-Wide Human SNP Array 6.0 (1000 k) (Santa Clara, CA, USA). Genotype calling was carried out using Affymetrix' Birdseed v2 algorithm with default quality thresholds. Samples with more than $5 \%$ missing genotypes, showing excess genetic dissimilarity to the remaining subjects, or with evidence for a cryptic relatedness to other study participants were removed. These quality control measures left 1213 control samples for inclusion in the replication cohort. All sex assignments could be verified by reference to the proportion of heterozygous SNPs on the X chromosome. Serum creatinine was available for 1140 individuals and was measured at the Institute for Clinical Chemistry in Kiel, Germany, using an enzymatic in vitro assay (CREAplus, Cobas $^{\circ}$, Roche Diagnostics, Indianapolis, IN).

The Korcula study included 944 unselected 18-98 year old Croatians, recruited into the study during 2007 from

Table 1 Characteristics of studies and study participants.

\begin{tabular}{|c|c|c|c|c|c|c|c|}
\hline \multirow[b]{2}{*}{ Study name } & \multicolumn{5}{|c|}{ EUROSPAN } & \multicolumn{2}{|c|}{ REPLICATION STUDIES } \\
\hline & ERF & MICROS & NSPHS & ORCADES & VIS & popgen & Korcula \\
\hline Nationality & The Netherlands & Italy & Sweden & UK & Croatia & Germany & Croatia \\
\hline Population type & isolated & isolated & isolated & isolated & isolated & general & isolated \\
\hline Genotyping platform & Illumina $318 \mathrm{~K}$ & Illumina $318 \mathrm{~K}$ & Illumina $318 \mathrm{~K}$ & Illumina $318 \mathrm{~K}$ & Illumina $318 \mathrm{~K}$ & Affymetrix $1000 \mathrm{~K}$ & Illumina $370 \mathrm{~K}$ \\
\hline Sample size* & 775 & 1086 & 653 & 718 & 774 & 1140 & 895 \\
\hline Females: n (\%) & $472(61 \%)$ & $615(57 \%)$ & $345(53 \%)$ & $385(54 \%)$ & $454(59 \%)$ & $534(47 \%)$ & $572(64 \%)$ \\
\hline Age: mean (sd) & $53(15)$ & $45(16)$ & $47(21)$ & $54(16)$ & $57(15)$ & $54(15)$ & $56(14)$ \\
\hline Diabetes: n (\%) & $36(4.9 \%)$ & $39(3.6 \%)$ & $44(6.7 \%)$ & $21(3.0 \%)$ & $72(9.4 \%)$ & $18(1.6 \%)$ & $93(10.3 \%)$ \\
\hline $\mathrm{AHT}^{\#}: \mathrm{n}(\%)$ & $190(24.5 \%)$ & $85(7.8 \%)$ & $124(19.0 \%)$ & $152(21.2 \%)$ & $192(25.2 \%)$ & Not available & $197(22.0 \%)$ \\
\hline \multicolumn{8}{|l|}{$\mathrm{S}_{\mathrm{CR}} \mathrm{mg} / \mathrm{dl}$ : mean (sd) } \\
\hline Males & $1.01(0.20)$ & $0.96(0.14)$ & $0.94(0.20)$ & $0.97(0.15)$ & $1.01(0.31)$ & $0.93(0.15)$ & $0.92(0.15)$ \\
\hline Females & $0.85(0.21)$ & $0.78(0.12)$ & $0.75(0.14)$ & $0.77(0.19)$ & $0.79(0.27)$ & $0.74(0.12)$ & $0.75(0.12)$ \\
\hline \multicolumn{8}{|l|}{$\mathrm{eGFR}^{\dagger} \mathrm{ml} / \mathrm{min} / 1.73 \mathrm{~m}^{2}$} \\
\hline Males & $81.1(19.0)$ & $87.8(15.1)$ & $92.2(22.1)$ & $84.3(16.0)$ & $82.0(19.4)$ & $88.0(17.5)$ & $77.1(14.9)$ \\
\hline Females & $75.8(20.5)$ & $83.4(16.8)$ & $88.7(19.2)$ & $81.5(18.5)$ & $81.0(19.8)$ & $85.5(17.2)$ & $72.4(14.1)$ \\
\hline
\end{tabular}

\footnotetext{
* Number of individuals with available creatinine, sex, and age information.

\# AHT: Anti-hypertensive treatment

${ }^{+}$Estimated using the updated abbreviated MDRD study equation [58]
} 
the island of Korcula [34]. The settlements on Korcula included the Eastern region of the island, which has a unique population history and has maintained a high level of isolation from other mainland populations and from the Western part of the island. Participants were phenotyped for $>400$ disease-related quantitative traits. Biochemical and physiological measurements were performed, genealogies reconstructed, questionnaires on lifestyle and environmental exposures collected, and blood samples and lymphocytes extracted and stored for further analyses. DNA was genotyped using the Illumina Infinium HumanCNV370v1 SNP bead microarrays. Serum creatinine as measured by the Jaffé rate method was available for 895 individuals.

\section{Statistical analysis}

To ensure normality within centers and comparability of $\mathrm{S}_{\mathrm{CR}}$ values across centers, we applied a quantile normalization in all discovery and replication studies, which involves ranking all $S_{C R}$ values and converting them to z-scores according to a standard normal distribution.

\section{Discovery stage}

To account for inter-individual relatedness within the five EUROSPAN cohorts, genome-wide association (GWA) analysis was carried out following a two stage approach. In the first stage, a sex- and age-adjusted linear model was fitted to the normalized $\mathrm{S}_{\mathrm{CR}}$ in order to estimate the residuals. A polygenic model was then fitted to estimate the inverse of the variance-covariance matrix, which accounts for the inter-individual relatedness and is based upon a genomic kinship matrix as described in Amin et al. [35]. The association between SNPs and residuals was assessed by means of an approximate score test statistic [36], assuming an additive model, as implemented in the GenABEL package [37]. The results from the five EUROSPAN cohorts were then combined into a fixed-effects meta-analysis with inverse-variance weighting, using MetABEL http://mga. bionet.nsc.ru/ yurii/ABEL/. Only SNPs that had a call rate $\geq 0.95$, a Hardy-Weinberg equilibrium (HWE) test $\mathrm{p}$ value $>10^{-6}$ and a minor allele frequency (MAF) $\geq$ 0.01 were included in the analyses. In total, 322,498 SNPs were tested for association with $\mathrm{S}_{\mathrm{CR}}$. The threshold for genome-wide statistical significance, according to Bonferroni adjustment for multiple testing, was set to $1.55 \times 10^{-7}$. Between-study heterogeneity was quantified using the $\mathrm{I}^{2}$ statistic, i.e. the percentage of total variation explained by heterogeneity rather than sampling error [38].

\section{Replication stage}

In the absence of clear methodological guidance on what may be the best strategy for passing SNPs to a replication stage, we selected SNPs for replication based on a tradeoff that enabled us to include our best findings from the discovery analysis, whilst avoiding the risk of an excessively long list. This was achieved by including all SNPs with a $\mathrm{p}$ value $\leq 10^{-5}$, but also allowing for SNPs with higher $\mathrm{p}$ values to get into the replication list in the presence of additional evidence for association provided by other SNPs within $100 \mathrm{~kb}$. The following criteria were applied: (i) at least one p value $\leq$ $10^{-5}$; (ii) at least one $\mathrm{p}$ value $\leq 10^{-4}$ and at least one additional SNP with $\mathrm{p}$ value $\leq 10^{-3}$ within $100 \mathrm{~kb}$; (iii) at least three SNPs with $\mathrm{p}$ value $\leq 10^{-3}$ within $100 \mathrm{~kb}$. For each group of candidate SNPs, we selected a candidate gene (all SNPs included in the gene were considered for replication) or region (all SNPs included within \pm 100 $\mathrm{kb}$ of the candidate SNPs were considered for replication) to test in the independent cohorts of Korcula and popgen. The complete workflow of the test procedure is depicted in Figure 1.

In popgen, the association between $\mathrm{S}_{\mathrm{CR}}$ and each SNP within a candidate region was assessed by means of a sex- and age-adjusted linear regression model assuming additive genetic effects, using PLINK version $1.05 \mathrm{http}: / /$ pngu.mgh.harvard.edu/purcell/plink/[39]. For Korcula, given that it is a family-based study, we used the same approach as described above for the EUROSPAN cohorts.

To assess the significance in the replication cohorts of associations with different SNPs from those genotyped in the discovery cohorts, we defined region-specific $\mathrm{p}$ values as follows: for a genomic region containing $N$ SNPs, we counted the number $n$ of SNPs that achieved $\mathrm{p}$ value $<0.05$. Assuming that $\mathrm{p}$ values are uniformly distributed between 0 and 1 under the null hypothesis of no association, the distribution function of $n, F($.$) , is$ that of a binomial with parameters $N$ and 0.05 . The region-specific $\mathrm{p}$ value then equals $1-F_{N, 0.05}(n-1)$. Given that in small genomic regions the assumption of independency is rarely met, the estimated $p$ value should be considered as conservative since the effective number of independent tests can only be lower than the total number of SNPs tested. Meta-analysis of region-specific $p$ values from popgen and Korcula was finally performed using the Fisher's combined probability test [40], which is suitable for combining tests performed in independent samples. We further evaluated rejection of the null hypothesis of no association based on a false discovery rate (FDR) of 0.05 [41], where $\mathrm{p}$ values are sorted in ascending order and the first $k$ tests with $\mathrm{p}$ value $\leq i /$ $m \times \alpha$ are considered significant (in our case, $i=1 . .29$, $m=29, \alpha=0.05$ ).

\section{Replication of previous findings}

We finally assessed whether any of the four loci reported to be associated with eGFR by Köttgen et al. [18] showed evidence for an association with $\mathrm{S}_{\mathrm{CR}}$ in our discovery meta-analysis. Köttgen et al. reported four 


\section{Meta-analysis of 5 EUROSPAN GWAS: 322,498 SNPs}

Genome-wide significance threshold: $0.05 / 322,498=1.55 \times 10^{-7}$

(1) Select SNPs promising for replication (hypothesis generation process):

(i) $\quad$ (i) $p$ value $<10^{-5}$

$\stackrel{\text { in }}{\text { in }} \quad$ (ii) $2 \mathrm{p}$ values, one $<10^{-4}$ and one $<10^{-3}$ within $100 \mathrm{~Kb}$

(iii) $3+p$ values $<10^{-3}$ within $100 \mathrm{~Kb}$

No. of SNPs identified $=\mathbf{9 1}$

\section{Using SNPs to identify genetic loci}

$\begin{array}{lll}\text { 1) SNP within a gene } & \text { 2) SNP close to a gene } & \text { 3) SNP in a gene desert }\end{array}$ ค

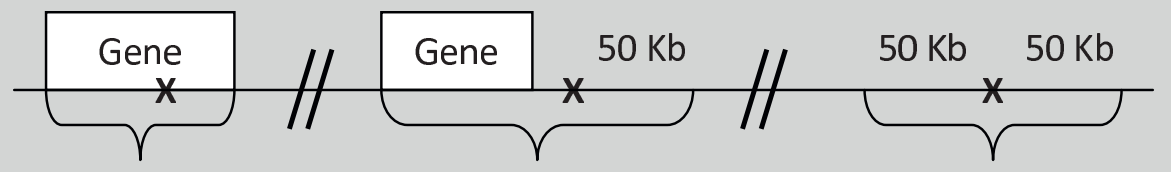

$\mathbf{2 9}$ loci identified: $\mathbf{1 4}$ within a gene; $\mathbf{8}$ close to a gene; $\mathbf{7}$ in a gene desert

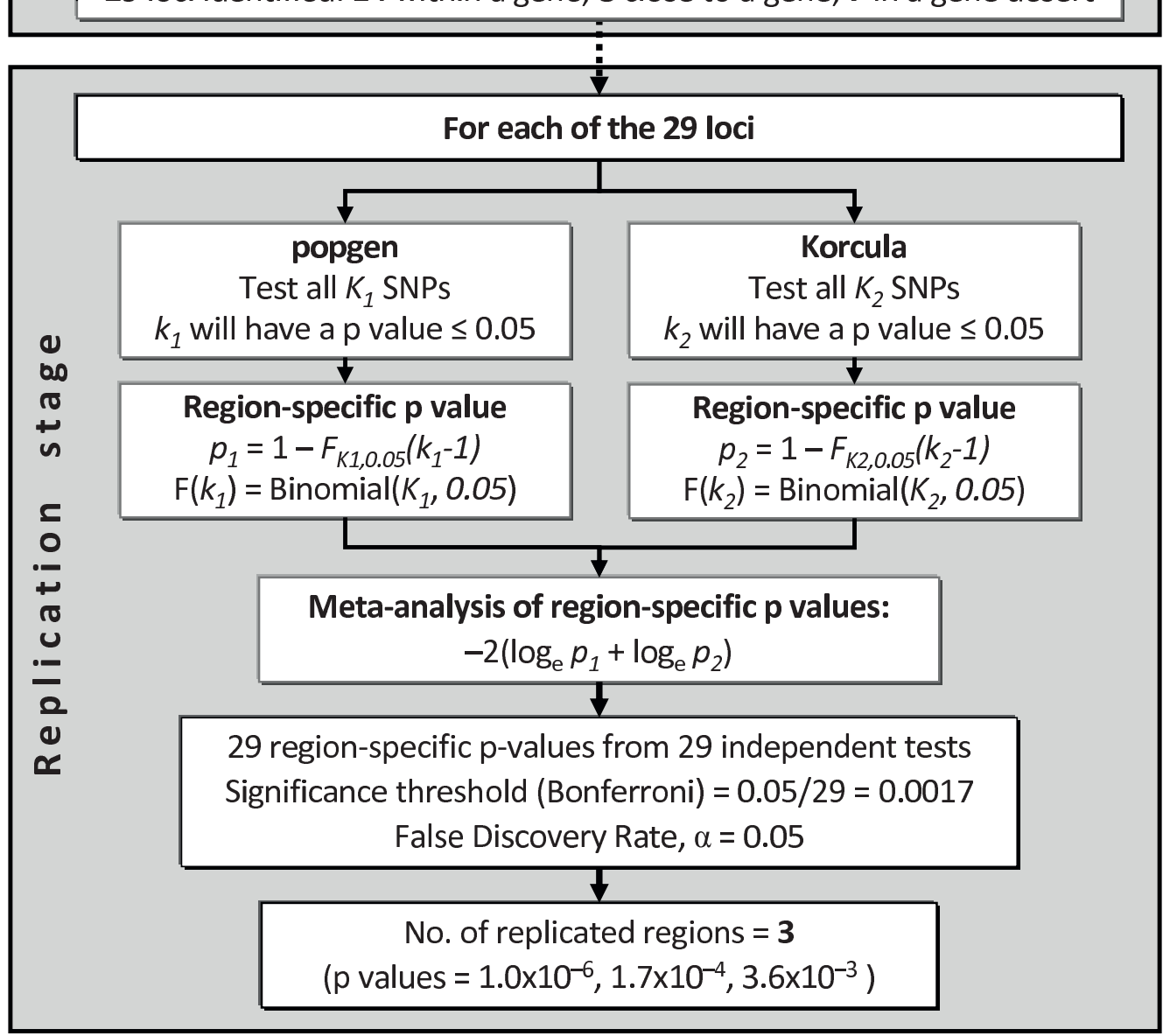

Figure 1 Workflow of the discovery and replication stages of the study (for details, see the Statistical Analysis section). 
SNPs to be associated with GFR: rs17319721 (SHROOM3), rs2467853 (SPATA5L1-GATM), rs12917707 (UMOD), and rs6040055 (JAG1). For each of the four SNPs, we defined LD blocks around them, following the method by Gabriel et al. [42] and using SNPs with MAF $\geq 1 \%$ from the HapMap-CEU database, Phase III/Release 2. Given that the genes were in four independent loci, the threshold for claiming significant replication, according to Bonferroni, was set to $0.05 / 4=$ 0.0125 . To compare our results with the commonly used method of testing replication at the same SNP or at a proxy SNP, we repeated the test procedure at one SNP per locus, using the same threshold for statistical significance.

If not specified otherwise, all data management, data analysis, programming, and the creation of graphs were performed using R 2.8.0 [43].

\section{Results}

Study-specific characteristics of the participants are reported in Table 1. A total of 4006 individuals were included in the meta-analysis whilst the replication cohorts comprised 2035 individuals. All EUROSPAN cohorts comprised a higher percentage of females (between $53 \%$ and 61\%) than males. The mean age ranged from 45 years in MICROS to 57 years in VIS. The replication samples had a similar age range, but a smaller percentage of females than males included in popgen.

The results of the GWA meta-analysis are depicted in Figure 2 . The genomic control factor $(\lambda)$, as assessed by the quantile-quantile plot included in Figure 2, was 1.004 $\left(\mathrm{SE}<10^{-5}\right)$, indicating that no cryptic relatedness or gross population structure affected our results [44].

The smallest $\mathrm{p}$ value in the meta-analysis was $1.5 \times$ $10^{-6}$ and was obtained for SNP rs2396463 in the collagen type IV alpha-3 (COL4A3) gene on chromosome $2 \mathrm{q}$. In the absence of hits of genome-wide significance, we selected a set of promising regions for follow-up in two independent replication samples, namely Korcula (an island population from Croatia) and popgen (a random population sample from the most northern part of

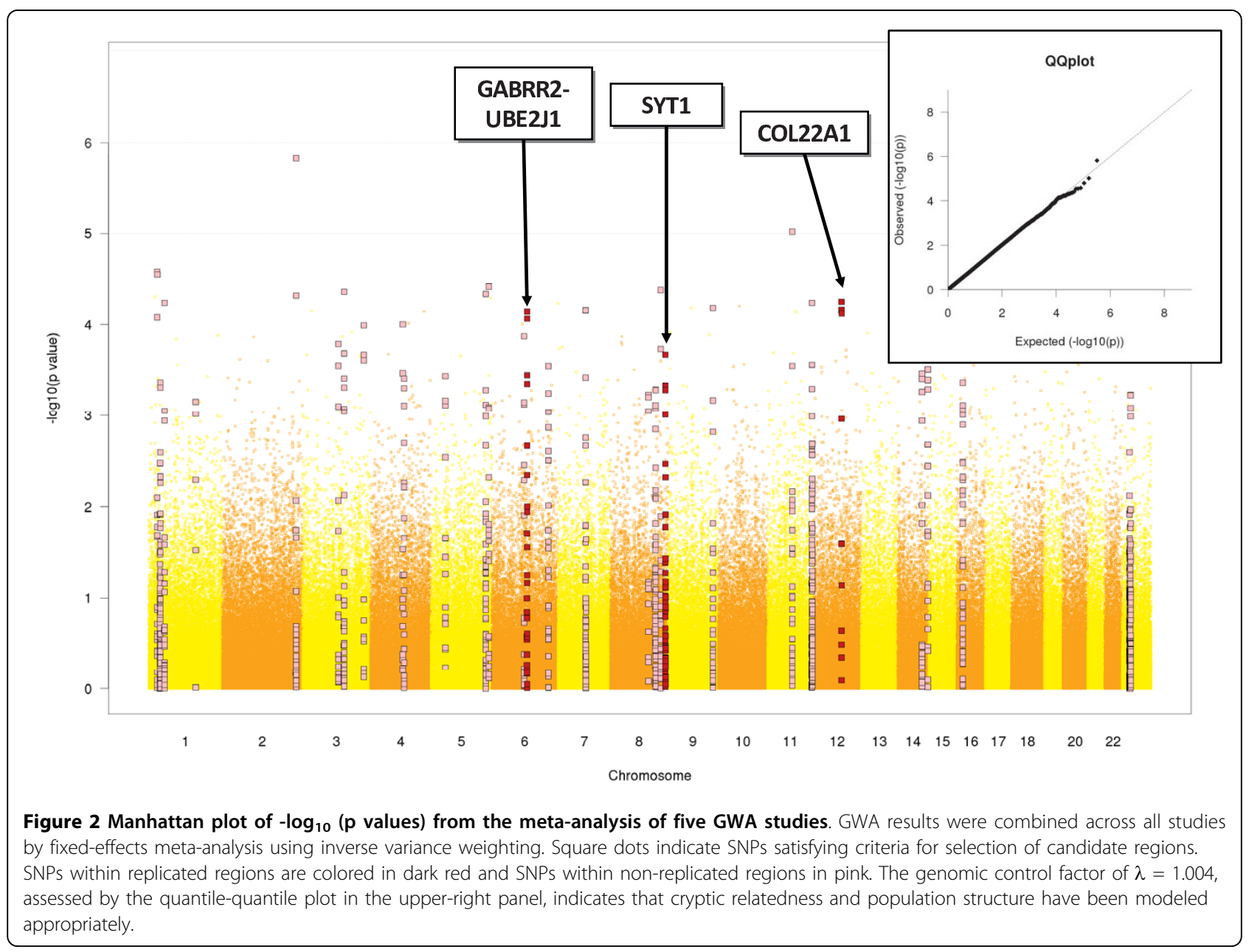


Germany). Twenty-nine genomic regions were considered for replication. The full list of regions and the results of the discovery meta-analysis are provided in the Additional file 1 - Table S1. Since the SNP panels genotyped in the replication samples differed from one another and from that used in the discovery GWA studies, all markers present in the candidate regions were included in the replication phase. A total of 2224 SNPs were analyzed in the popgen samples and 1136 SNPs were analyzed in the Korcula samples. Results of the replication analysis are fully reported in the Additional file 1 - Table S2, with loci sorted by significance.

Two candidate regions from the discovery GWA studies also showed significant evidence for an association with $S_{C R}$ level in the popgen and Korcula samples after Bonferroni correction for multiple testing of the combined $\mathrm{p}$ value (significance threshold for 29 independent tests: $\alpha=0.0017)$. When controlling for the FDR, i.e. for the probability of reporting a false positive result, a third region could be added to the list of replicated findings (Figure 3).

The first replicated region was defined by four SNPs (rs4075073, rs4588898, rs9324496, and rs2873682) in the collagen type XXII alpha 1 (COL22A1) gene, all of which yielded $\mathrm{p}$ values $\leq 9.79 \times 10^{-4}$ in the meta-analysis of the discovery stage, with homogeneous effects observed across populations: $\mathrm{I}^{2}=0 \%$ for all the four SNPs. A forest plot of the marker with the strongest evidence for association, SNP rs4588898, is provided in Figure 4A. Six other SNPs in the gene (out of 72) had $\mathrm{p}$ values between $3.42 \times 10^{-3}$ and 0.0414 (Table 2). As it can be inferred from Figure 5, some 19 of 140 COL22A1 SNPs genotyped in popgen were found to be significantly associated with $\mathrm{S}_{\mathrm{CR}}$ (red squares), as were 11 out of 71 SNPs in Korcula (green squares). Fisher's combined probability test $\mathrm{p}$ value was $1.0 \times 10^{-6}$. Nevertheless, the gene regions with the strongest $\mathrm{S}_{\mathrm{CR}}$ association in EUROSPAN and either popgen or Korcula failed

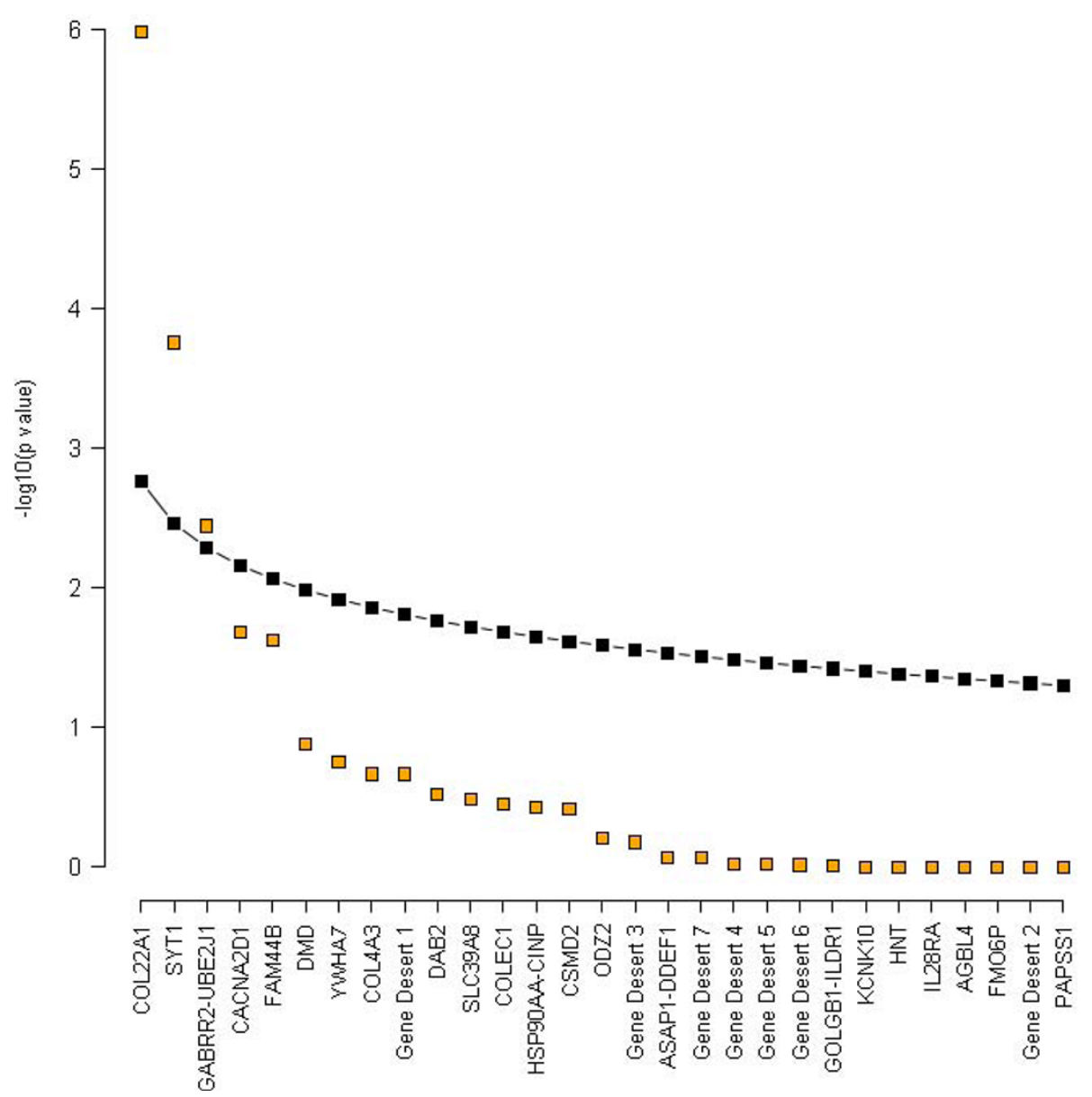

Figure 3 Results of the false discovery rate analysis. $\log _{10}$ (Fisher $p$ value) of the replication analysis (orange) and -log $\log _{10}$ (significance thresholds) for FDR (black) are plotted for each candidate locus. According to [41], FDR thresholds have been calculated as $\mathrm{i} / \mathrm{m} \times \alpha$, with $\alpha=$ $0.05, m=$ no. of test (i.e.: no. of regions, 29), and $i$ ranging between 1 and 29. After sorting the Fisher $p$ values in ascending order, the first $k$ tests for which the $p$ value is $\leq$ threshold are significant. 


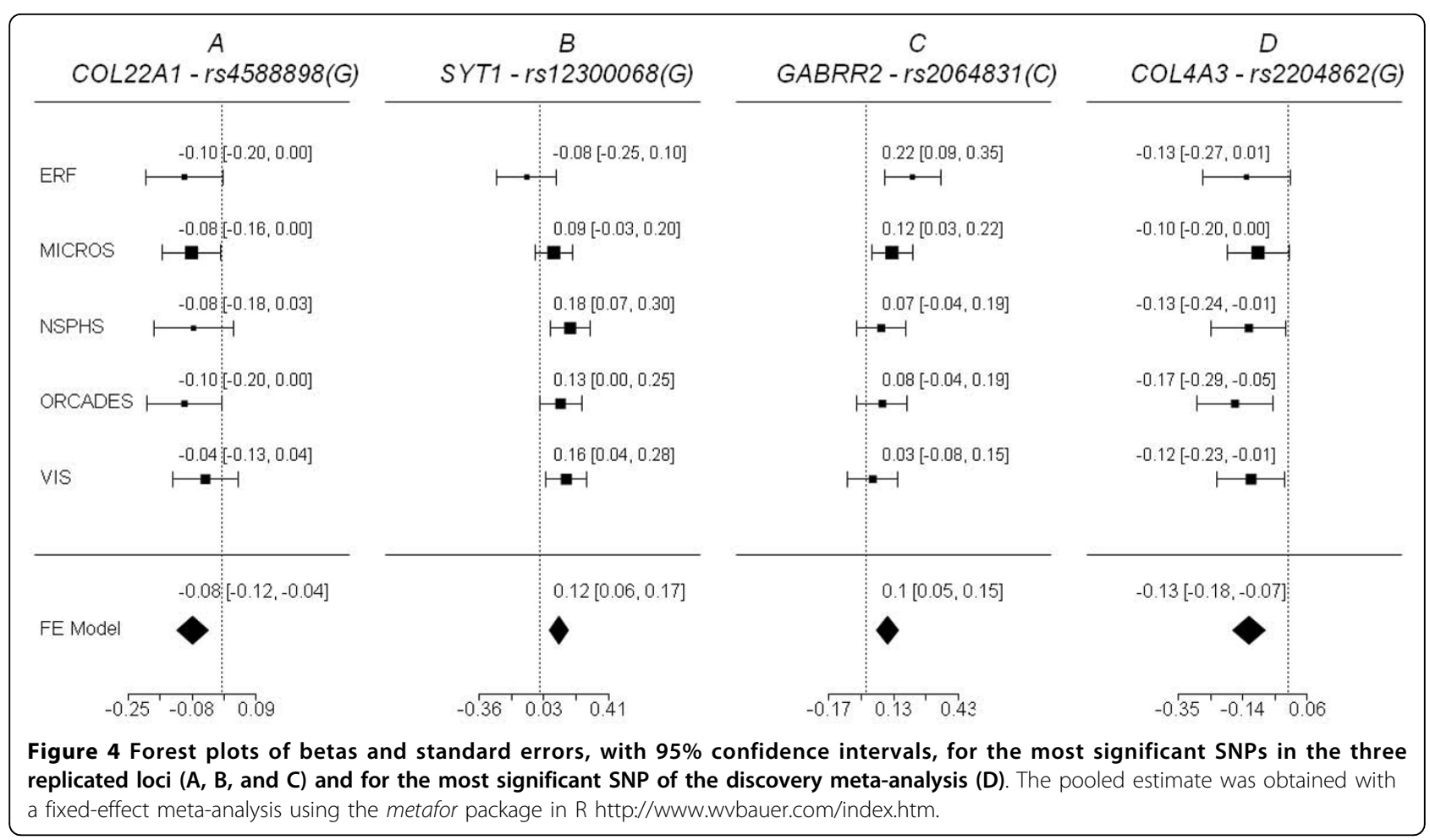

to overlap and were found to be located in distinct LD blocks. Interestingly, however, the smallest $\mathrm{p}$ values for popgen and Korcula fell into the same LD block.

Three closely linked SNPs (rs10506807, rs12300068, and rs11112829) on chromosome 12q21, yielded $\mathrm{p}$ values $\leq 7.55 \times 10^{-5}$ in the EUROSPAN discovery meta-analysis. $\mathrm{I}^{2}$ for heterogeneity was $21.88 \%, 24.11 \%$, and $19.94 \%$, respectively, none of which was statistically significant. A forest plot for SNP rs12300068 is provided in Figure 4B. Depending upon the annotation of the 5'UTR sequence, all SNPs are located either $>100 \mathrm{~kb}$ upstream (NCBI) or directly inside (Ensembl and UCSC) the synaptotagmin-1 (SYT1) gene. In the popgen sample, nine SNPs located less than $50 \mathrm{~kb}$ upstream of the three discovery SNPs were significantly associated with $\mathrm{S}_{\mathrm{CR}}$, with $\mathrm{p}$ values between $2.0 \times 10^{-5}$ and $8.5 \times$ $10^{-3}$ (Table 3 ). The Fisher's combined probability test $\mathrm{p}$ value for the whole region was as low as $1.7 \times 10^{-4}$.

The third locus was defined by the four SNPs rs3777514 $\left(\mathrm{p}\right.$ value $\left.=4.5 \times 10^{-4}\right)$, rs2064831 $(\mathrm{p}$ value $=$ $\left.7.2 \times 10^{-5}\right)$, rs1998576 $\left(\mathrm{p}\right.$ value $\left.=8.6 \times 10^{-5}\right)$, and rs7744005 ( $\mathrm{p}$ value $\left.=3.6 \times 10^{-4}\right)$. The effect of the three SNPs upon $\mathrm{S}_{\mathrm{CR}}$ level was homogeneous across populations, with an $\mathrm{I}^{2}$ of $2.20 \%$ ( $\mathrm{p}$ value $\left.=0.38\right), 6.73 \%(\mathrm{p}$ value $=0.29), 9.70 \%(\mathrm{p}$ value $=0.38)$, and $0.00 \%(\mathrm{p}$ value $=0.54$ ), respectively. A forest plot of the SNP with the strongest evidence for association (rs2064831), is reported in Figure 4C. The SNPs in question are located in a region on chromosome $6 \mathrm{q} 15$ containing the gamma-aminobutyric acid receptor rho-2 (GABRR2) and the ubiquitin-conjugating enzyme E2-J1 (UBE2J1) genes (Figure 6). Five additional SNPs (out of a total of 28 SNPs tested) in this region had p values between $2.2 \times$ $10^{-3}$ and 0.0280 (Table 4). Of the 37 SNPs genotyped in the popgen sample, eight were associated with $\mathrm{S}_{\mathrm{CR}}$ with a $\mathrm{p}$ value $\leq 0.05$; seven of them overlapped with the GABRR2 and UBE2J1 genes (see the blue squares in Figure 6). The most consistent association signals in EUROSPAN and popgen were found near the GABRR2 gene and its promoter, and the respective SNPs were in linkage disequilibrium $\left(r^{2}>0.59\right.$, Figure 6 , middle panel). SNP rs12195070 was genotyped in both EUROSPAN and popgen: effect direction was discordant but in both cases association was very significant with $\mathrm{p}$ values of $4.5 \times 10^{-3}$ in EUROSPAN and $\mathrm{p}$ value $=7.2$ $\times 10^{-3}$ in popgen, respectively. In the Korcula samples, the smallest $p$ value in the region was 0.0616 so that we cannot formally claim replication in this population. However, Fisher's combined probability test $p$ value equaled $3.6 \times 10^{-3}$. This value does not meet the Bonferroni threshold for multiple testing, but it does meet the FDR threshold of 0.0052 , which controls the probability of reporting false positives at a 0.05 level (see Additional file 1 - Table S2 and Figure 3). Detailed results for this locus are reported in Table 4.

Although consistently observed in all EUROSPAN populations (Figure 4D), the association noted between $\mathrm{S}_{\mathrm{CR}}$ and the COL4A3 gene could not be verified in the 
Table 2 SNPs showing the highest evidence of association in the COL22A1 gene (chromosome 8).

\begin{tabular}{|c|c|c|c|c|c|c|c|c|}
\hline study & name & position & Genotype (Ref. All.) & Ref. All. Freq. & $\mathbf{n}$ & Beta* & SE & p value $* *$ \\
\hline EUROSPAN & rs4075073 & 139808143 & $A / C(A)$ & 0.37 & 3996 & 0.0671 & 0.0203 & $9.8 \times 10^{-4}$ \\
\hline EUROSPAN & rs4588898 & 139815390 & $A / G(A)$ & 0.30 & 3999 & 0.0786 & 0.0212 & $2.1 \times 10^{-4}$ \\
\hline EUROSPAN & rs13255079 & 139828786 & $C / T(T)$ & 0.16 & 4001 & 0.0769 & 0.0263 & $3.4 \times 10^{-3}$ \\
\hline EUROSPAN & rs9324496 & 139833578 & $C / T(T)$ & 0.34 & 3995 & 0.0716 & 0.0205 & $4.6 \times 10^{-4}$ \\
\hline EUROSPAN & rs7824025 & 139839898 & $A / C(A)$ & 0.07 & 3998 & 0.0762 & 0.0374 & 0.0414 \\
\hline EUROSPAN & rs2873682 & 139840693 & $A / G(A)$ & 0.30 & 2610 & 0.0915 & 0.0264 & $5.2 \times 10^{-4}$ \\
\hline EUROSPAN & rs11166844 & 139848062 & $C / T(C)$ & 0.39 & 3993 & 0.0485 & 0.0202 & 0.0166 \\
\hline EUROSPAN & rs1574172 & 139941802 & $A / G(A)$ & 0.14 & 3998 & -0.0713 & 0.0284 & 0.0122 \\
\hline EUROSPAN & rs4736078 & 139944298 & $C / T(C)$ & 0.22 & 3996 & -0.0503 & 0.0242 & 0.0373 \\
\hline EUROSPAN & rs6986041 & 139988449 & $C / T(C)$ & 0.35 & 3936 & -0.0583 & 0.0207 & $4.8 \times 10^{-3}$ \\
\hline POPGEN & rs4282617 & 139795530 & $\mathrm{C} / \mathrm{G}(\mathrm{C})$ & 0.25 & 1139 & -0.0822 & 0.0398 & 0.0391 \\
\hline POPGEN & rs10092896 & 139856976 & $\mathrm{C} / \mathrm{T}(\mathrm{C})$ & 0.27 & 1139 & -0.1123 & 0.0380 & $3.1 \times 10^{-3}$ \\
\hline POPGEN & rs2318334 & 139859320 & $\mathrm{C} / \mathrm{T}(\mathrm{C})$ & 0.25 & 1140 & -0.1115 & 0.0390 & $4.2 \times 10^{-3}$ \\
\hline POPGEN & rs1574370 & 139866164 & $A / G(A)$ & 0.24 & 1126 & -0.0992 & 0.0402 & 0.0137 \\
\hline POPGEN & rs6991720 & 139871695 & $\mathrm{C} / \mathrm{G}(\mathrm{G})$ & 0.25 & 1139 & -0.1074 & 0.0391 & $6.1 \times 10^{-3}$ \\
\hline POPGEN & rs7837787 & 139875897 & $\mathrm{~A} / \mathrm{G}(\mathrm{G})$ & 0.25 & 1140 & -0.1106 & 0.0391 & $4.7 \times 10^{-3}$ \\
\hline POPGEN & rs12155960 & 139886087 & $\mathrm{~A} / \mathrm{G}(\mathrm{G})$ & 0.26 & 1134 & -0.1152 & 0.0388 & $3.0 \times 10^{-3}$ \\
\hline POPGEN & rs11779129 & 139888085 & $A / C(A)$ & 0.25 & 1140 & -0.0992 & 0.0388 & 0.0105 \\
\hline POPGEN & rs16893541 & 139890024 & $\mathrm{C} / \mathrm{G}(\mathrm{C})$ & 0.27 & 1124 & -0.1089 & 0.0390 & $5.2 \times 10^{-3}$ \\
\hline POPGEN & rs12549194 & 139896019 & $A / C(C)$ & 0.26 & 1137 & -0.0830 & 0.0388 & 0.0327 \\
\hline POPGEN & rs10093925 & 139904787 & $C / T(T)$ & 0.36 & 1124 & -0.0687 & 0.0347 & 0.0478 \\
\hline POPGEN & rs6577953 & 139914021 & $\mathrm{C} / \mathrm{G}(\mathrm{C})$ & 0.40 & 1139 & -0.1032 & 0.0336 & $2.1 \times 10^{-3}$ \\
\hline POPGEN & rs6993839 & 139914702 & $\mathrm{~A} / \mathrm{G}(\mathrm{G})$ & 0.39 & 1131 & -0.1029 & 0.0342 & $2.6 \times 10^{-3}$ \\
\hline POPGEN & rs9650564 & 139918011 & $C / T(C)$ & 0.41 & 1139 & -0.1017 & 0.0338 & $2.6 \times 10^{-3}$ \\
\hline POPGEN & rs9650565 & 139918089 & $\mathrm{C} / \mathrm{T}(\mathrm{C})$ & 0.41 & 1133 & -0.0944 & 0.0339 & $5.3 \times 10^{-3}$ \\
\hline POPGEN & rs7014497 & 139923457 & $\mathrm{C} / \mathrm{T}(\mathrm{C})$ & 0.39 & 1133 & -0.0892 & 0.0341 & $8.9 \times 10^{-3}$ \\
\hline POPGEN & rs9650566 & 139923872 & $\mathrm{~A} / \mathrm{G}(\mathrm{G})$ & 0.46 & 1139 & -0.1054 & 0.0332 & $1.5 \times 10^{-3}$ \\
\hline POPGEN & rs17740495 & 139941879 & $\mathrm{C} / \mathrm{T}(\mathrm{C})$ & 0.08 & 1136 & 0.1393 & 0.0603 & 0.0209 \\
\hline POPGEN & rs16893545 & 139948143 & $A / C(C)$ & 0.18 & 1140 & 0.0953 & 0.0440 & 0.0304 \\
\hline KORCULA & rs4076439 & 139690550 & $\mathrm{~A} / \mathrm{G}(\mathrm{G})$ & 0.25 & 895 & 0.0907 & 0.0393 & 0.0209 \\
\hline KORCULA & rs4341165 & 139692067 & $C / T(C)$ & 0.25 & 895 & 0.0907 & 0.0393 & 0.0209 \\
\hline KORCULA & rs4909439 & 139727929 & $C / T(C)$ & 0.17 & 895 & 0.1080 & 0.0518 & 0.0371 \\
\hline KORCULA & rs3923549 & 139732799 & $C / T(T)$ & 0.10 & 895 & 0.1513 & 0.0704 & 0.0316 \\
\hline KORCULA & rs4073446 & 139735056 & $C / T(T)$ & 0.11 & 895 & 0.1555 & 0.0658 & 0.0182 \\
\hline KORCULA & rs7839680 & 139762863 & $A / G(A)$ & 0.18 & 895 & 0.0950 & 0.0472 & 0.0440 \\
\hline KORCULA & rs4909444 & 139770391 & $\mathrm{G} / \mathrm{T}(\mathrm{T})$ & 0.38 & 895 & 0.0623 & 0.0289 & 0.0309 \\
\hline KORCULA & rs4074052 & 139785008 & $C / T(T)$ & 0.46 & 894 & -0.0504 & 0.0248 & 0.0419 \\
\hline KORCULA & rs10112806 & 139806115 & $\mathrm{~A} / \mathrm{C}(\mathrm{C})$ & 0.41 & 895 & -0.0589 & 0.0280 & 0.0357 \\
\hline KORCULA & rs1320279 & 139899978 & $C / T(C)$ & 0.11 & 895 & -0.1823 & 0.0662 & $5.9 \times 10^{-3}$ \\
\hline KORCULA & rs2318345 & 139970360 & $C / T(C)$ & 0.09 & 894 & 0.1755 & 0.0720 & 0.0147 \\
\hline
\end{tabular}

\# association models were adjusted for age and sex; *in standard deviations; **p value: for EUROSPAN, the $p$ value refers to the meta-analysis of the five individual GWA studies, for popgen and Korcula, the $\mathrm{p}$ value is from the linear regression analysis (for details, see Methods).

replication cohorts (Fisher's combined probability test $\mathrm{p}$ value $=0.216$ )

Unfortunately, the number of people with diabetes included in the EUROSPAN populations was too small to allow any meaningful subgroup analysis, adjusting for disease state. However, when we repeated our GWA meta-analysis in non-diabetic subjects only, the $\mathrm{p}$ values for the three replicated gene regions changed so little that any strong interaction of the respective loci with diabetes status appears rather unlikely.

Results of the replication analysis at the four loci reported to be associated with eGFR by Köttgen et al. [18] are reported in the Additional file 1 - Table S3. We identified three SNPs in the UMOD gene locus: 


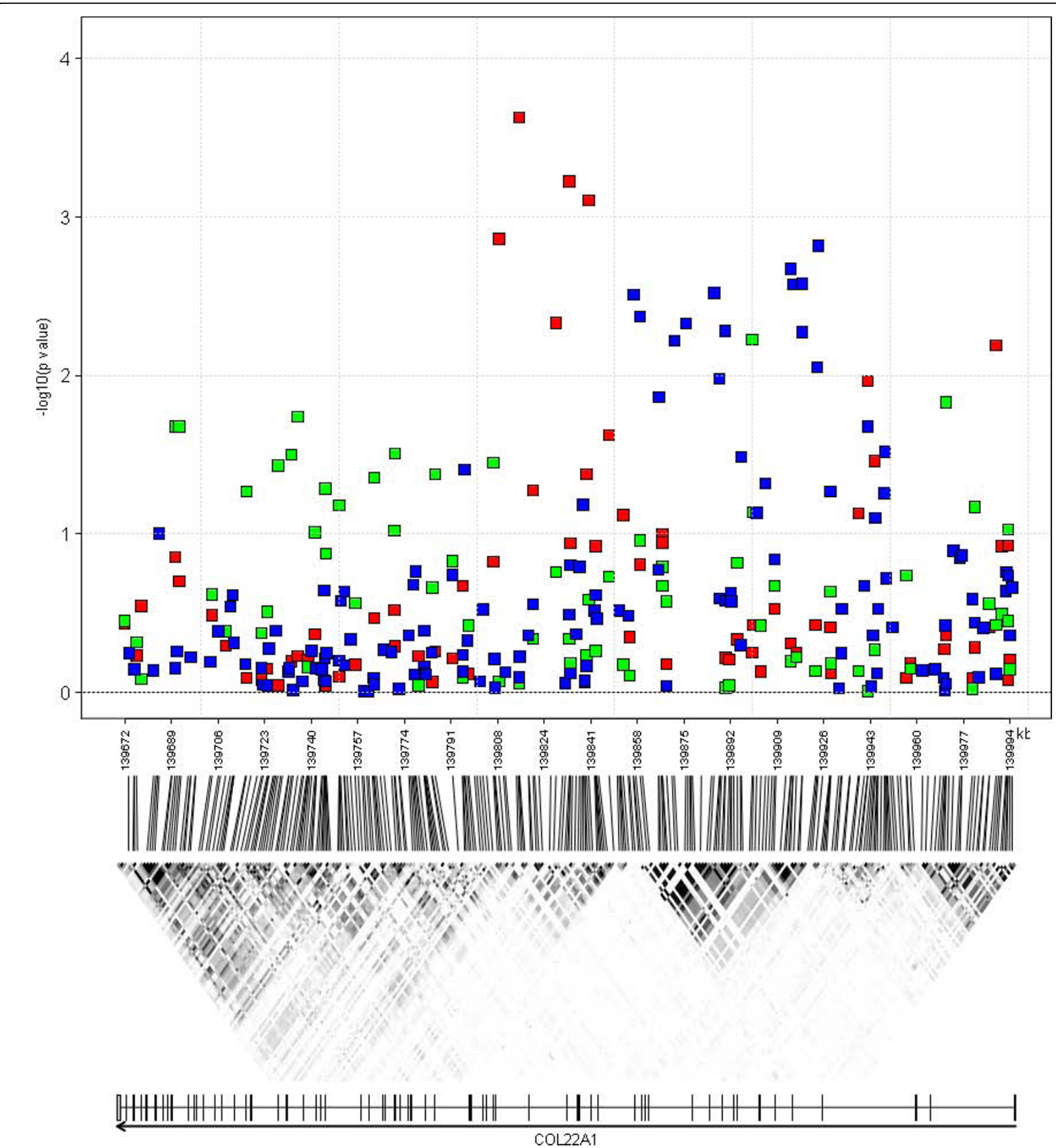

Figure 5 Genomic structure and association results at the COL22A1 locus. Upper panel: $-\log _{10}(p$ values) are plotted by physical position for the EUROSPAN discovery meta-analysis (red squares), the popgen (blue squares) and the Korcula (green squares) replication cohorts. Middle panel: linkage disequilibrium (LD) as quantified by $r^{2}$ (the higher the LD, the darker the color, with black indicating perfect LD), based upon the HapMap-CEU database, Phase III/Release 2, (NCBI build 36). Lower panel: genes located in the plotted region, with coding exons indicated by black rectangles and orientation.

rs4293393 was significantly associated with $\mathrm{S}_{\mathrm{CR}}$ level (p value $\left.=3.9 \times 10^{-4}\right)$ and weaker signals were observed for rs11647727 $(\mathrm{p}$ value $=0.011)$ and $\mathrm{rs} 4506906(\mathrm{p}$ value $=$ 0.028 ). The region-specific $\mathrm{p}$ value for this locus was $1.3 \times 10^{-4}$. Of the five SNPs identified in the SPATA5L1-GATM locus, rs1153860, rs1346268, and rs1719247 were associated with $\mathrm{S}_{\mathrm{CR}}$ at $\mathrm{p}$ values of $5.0 \times$ $10^{-4}, 1.9 \times 10^{-3}$, and $4.6 \times 10^{-3}$, respectively (region-specific p value $=1.2 \times 10^{-3}$ ). At the SCHROOM3 gene locus, 53 SNPs were tested: three of them resulted in a $\mathrm{p}$ value $\leq 0.05$ (region-specific $\mathrm{p}$ value $=0.50)$. The smallest $\mathrm{p}$ value of $1.7 \times 10^{-3}$ was observed for SNP 
Table 3 SNPs with the highest evidence of association in the region upstream the SYT1 gene.\#

\begin{tabular}{|c|c|c|c|c|c|c|c|c|}
\hline Study & name & position & Genotype (Ref. All.) & Ref. All. Freq. & $\mathbf{n}$ & Beta* & SE & $p$ value ${ }^{* *}$ \\
\hline EUROSPAN & rs11838060 & 77997790 & $\mathrm{G} / \mathrm{T}(\mathrm{T})$ & 0.14 & 3163 & -0.0696 & 0.0312 & 0.0258 \\
\hline EUROSPAN & rs10506807 & 78005428 & $\mathrm{C} / \mathrm{T}(\mathrm{C})$ & 0.13 & 4000 & -0.1141 & 0.0287 & $7.0 \times 10^{-5}$ \\
\hline EUROSPAN & rs12300068 & 78005502 & $A / G(A)$ & 0.13 & 3997 & -0.1158 & 0.0288 & $5.7 \times 10^{-5}$ \\
\hline EUROSPAN & rs7972593 & 78013149 & $C / T(T)$ & 0.12 & 3989 & -0.0978 & 0.0300 & $1.1 \times 10^{-3}$ \\
\hline EUROSPAN & rs11112829 & 78029267 & $\mathrm{C} / \mathrm{T}(\mathrm{C})$ & 0.13 & 4000 & -0.1135 & 0.0287 & $7.5 \times 10^{-5}$ \\
\hline POPGEN & rs 12312807 & 77957336 & $\mathrm{~A} / \mathrm{G}(\mathrm{A})$ & 0.11 & 1139 & 0.1480 & 0.0539 & $6.1 \times 10^{-3}$ \\
\hline POPGEN & rs1527119 & 77964145 & $\mathrm{G} / \mathrm{T}(\mathrm{G})$ & 0.11 & 1139 & 0.1471 & 0.0539 & $6.4 \times 10^{-3}$ \\
\hline POPGEN & rs1033196 & 77966968 & $C / T(T)$ & 0.14 & 1128 & 0.1320 & 0.0479 & $5.8 \times 10^{-3}$ \\
\hline POPGEN & rs2950383 & 77973538 & $A / G(A)$ & 0.37 & 1103 & -0.1553 & 0.0359 & $2.0 \times 10^{-5}$ \\
\hline POPGEN & rs1356022 & 77974533 & $\mathrm{C} / \mathrm{T}(\mathrm{C})$ & 0.14 & 1140 & 0.1300 & 0.0475 & $6.2 \times 10^{-3}$ \\
\hline POPGEN & rs12317960 & 77977824 & $C / T(T)$ & 0.14 & 1140 & 0.1249 & 0.0474 & $8.5 \times 10^{-3}$ \\
\hline POPGEN & rs10506806 & 77979113 & $C / T(T)$ & 0.31 & 1120 & 0.1012 & 0.0362 & $5.1 \times 10^{-3}$ \\
\hline POPGEN & rs11610381 & 77979918 & $\mathrm{C} / \mathrm{T}(\mathrm{C})$ & 0.14 & 1134 & 0.1321 & 0.0476 & $5.5 \times 10^{-3}$ \\
\hline POPGEN & rs7971081 & 77980051 & $\mathrm{C} / \mathrm{T}(\mathrm{C})$ & 0.14 & 1140 & 0.1296 & 0.0474 & $6.3 \times 10^{-3}$ \\
\hline
\end{tabular}

\# association models were adjusted for age and sex; ${ }^{* i n}$ standard deviations; ${ }^{* *} p$ value: for EUROSPAN, the $p$ value refers to the meta-analysis of the five individual GWA studies, for popgen, the $\mathrm{p}$ value is from the linear regression analysis (for details, see Methods).

rs4859682 (this SNP was in strong LD with the rs17319721 reported in the paper, $\left.\mathrm{r}^{2}=0.94\right)$. None of the 8 polymorphisms tested in the JAG1 gene was significantly associated with $\mathrm{S}_{\mathrm{CR}}$ level, including the rs6040055 which was included in our database as well. Our conclusions would have been slightly different had we attempted replication at the level of the individual variants rather than at the locus level. In this case, also the SCHROOM3 locus would have been replicated.

\section{Discussion}

The main result of our study was the identification of three novel genetic associations with $S_{C R}$ level. These were detected in a meta-analysis of five European isolated population samples and replicated in two independent population samples, one from the general CentralEuropean population (popgen), and one from another isolate (Korcula). The replicated loci included the COL22A1 gene on chromosome 8 and the SYT1 gene on chromosome 12 . The third locus, including the GABRR2 and UBE2J1 genes on chromosome 6, showed substantial evidence of association as well. In addition, the association of two loci (UMOD and SPATA5L1GATM) and one SNP in the SCHROOM3 locus, previously reported with GFR, was also found to apply to $\mathrm{S}_{\mathrm{CR}}$. This confirmation also supports our choice of using $S_{C R}$ adjusted by age and sex which is equivalent to study GFR calculated from $S_{C R}$ weighted by age and sex [1] (black or white ethnicity, which should also be accounted for, was not relevant in our study involving individuals of European origin).

The two SNPs with the strongest evidence for association in the discovery stage of our study were located in the promoter region of the $C O L 4 A 3$ gene, which is expressed in the glomerular basement membrane (GBM) of the kidney, and which has been associated with Alport syndrome, Goodpasture syndrome [45] and benign hematuria [46]. Despite making biological sense, however, the association between COL4A3 and $\mathrm{S}_{\mathrm{CR}}$ as observed in our meta-analysis could not be verified in the replication stage. On the one hand, this could be interpreted to indicate that no common variants of that gene are involved in the regulation of kidney function. On the other hand, the lack of replication could be due either to the involvement of the gene in regulatory pathways, implying a strong interaction with other genes, or to a particularly prominent interaction with populationspecific environmental conditions [47].

In any case, a slightly less significant association between three other genes and $S_{C R}$ from the discovery meta-analysis could be replicated in either the popgen or the Korcula data. Different SNPs in the COL22A1 gene were found to be associated with $S_{C R}$ in all discovery and replication cohorts. This association may reflect the biological relationship between muscle mass formation and creatinine levels. In fact, in situ hybridization of myotendinous junctions has revealed that muscle cells produce collagen XXII, and functional tests have shown that collagen XXII acts as a cell adhesion ligand for skin epithelial cells and fibroblasts [48].

The discovery stage association of $\mathrm{S}_{\mathrm{CR}}$ with the $S Y T 1$ gene was well replicated in the popgen sample. Even though the annotation of gene reference sequences is not uniform across different databases (NCBI, UCSC, Ensembl), the associated SNPs are located in the fourth and last intron of the 5' SYT1 un-translated region 


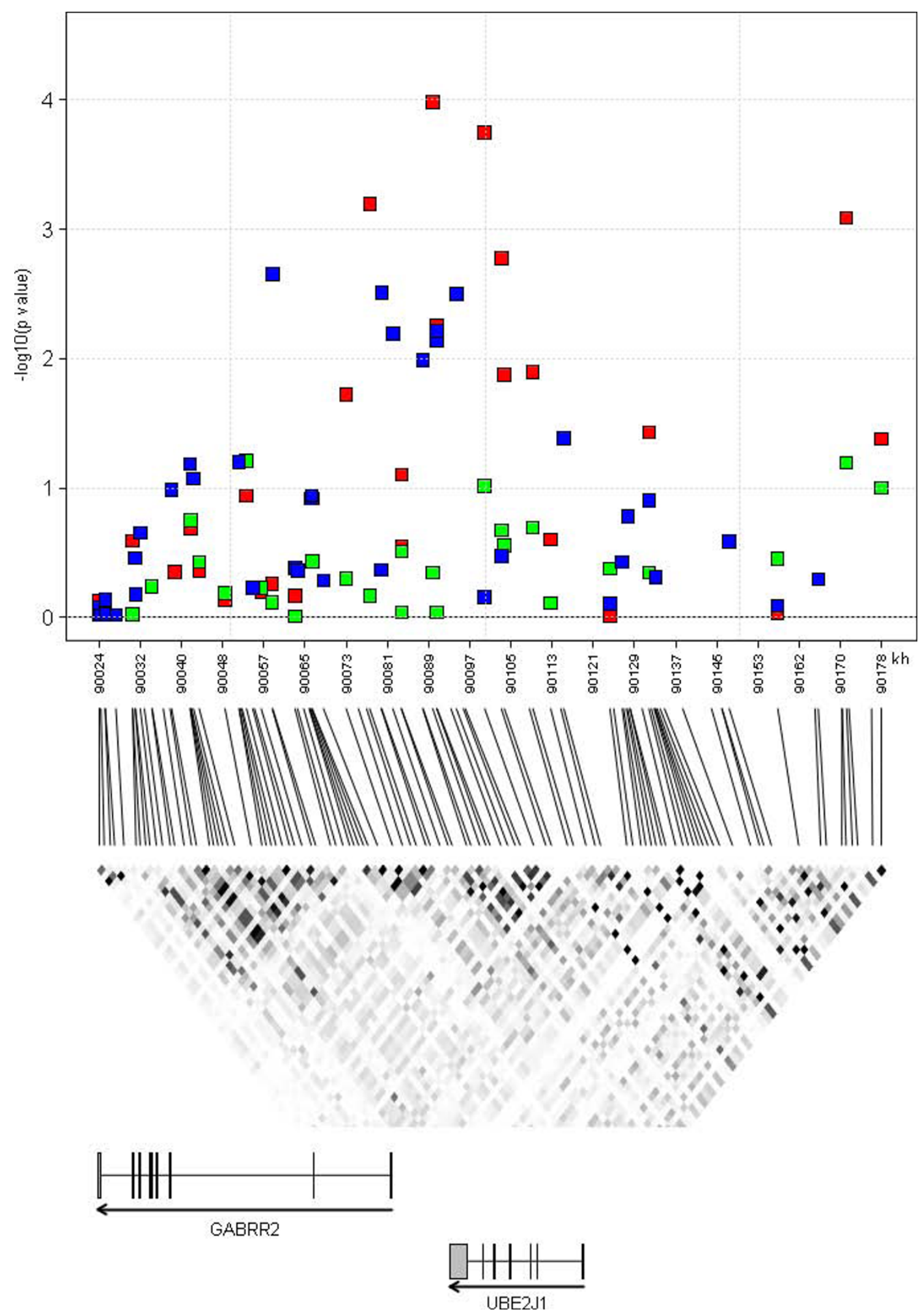

Figure 6 Genomic structure and association results at the GABRR2-UBE2J1 locus. Upper panel: - $\log _{10}(p$ values) are plotted by physical position for the EUROSPAN discovery meta-analysis (red squares), the popgen (blue squares) and the Korcula (green squares) replication cohorts. Middle panel: linkage disequilibrium (LD) as quantified by $r^{2}$ (the higher the LD, the darker the color, with black indicating perfect LD), based upon the HapMap-CEU database, Phase III/Release 2, (NCBI build 36). Lower panel: genes located in the plotted region, with coding exons indicated by black rectangles and orientation. 
Table 4 SNPs with the highest evidence of association in the region including the GABRR2 and the UBE2J1 genes (chromosome 6)".

\begin{tabular}{|c|c|c|c|c|c|c|c|c|c|}
\hline Study & GENE & name & Position & Genotype (Ref. All.) & Ref. All. Freq. & $\mathbf{N}$ & Beta* & SE & $p$ value ${ }^{* *}$ \\
\hline EUROSPAN & GABRR2 & rs6942204 & 90072687 & $\mathrm{C} / \mathrm{T}(\mathrm{C})$ & 0.34 & 4001 & 0.0497 & 0.0213 & 0.0196 \\
\hline EUROSPAN & GABRR2 & rs3777514 & 90077300 & $A / C(A)$ & 0.20 & 3998 & 0.0855 & 0.0244 & $4.5 \times 10^{-4}$ \\
\hline EUROSPAN & Intergenic & rs2064831 & 90089661 & $\mathrm{C} / \mathrm{T}(\mathrm{C})$ & 0.18 & 3995 & 0.1018 & 0.0257 & $7.2 \times 10^{-5}$ \\
\hline EUROSPAN & Intergenic & rs12195070 & 90090455 & $C / T(T)$ & 0.19 & 3998 & 0.0722 & 0.0254 & $4.5 \times 10^{-3}$ \\
\hline EUROSPAN & UBE2J1 & rs1998576 & 90099856 & $A / G(A)$ & 0.18 & 3997 & 0.0993 & 0.0253 & $8.6 \times 10^{-5}$ \\
\hline EUROSPAN & UBE2J1 & rs12189673 & 90103123 & $\mathrm{C} / \mathrm{T}(\mathrm{C})$ & 0.30 & 3980 & -0.0653 & 0.0213 & $2.2 \times 10^{-3}$ \\
\hline EUROSPAN & UBE2J1 & rs1065657 & 90103732 & $C / T(T)$ & 0.45 & 3999 & 0.0499 & 0.0197 & 0.0115 \\
\hline EUROSPAN & UBE2J1 & rs7760851 & 90109323 & $\mathrm{~A} / \mathrm{G}(\mathrm{G})$ & 0.49 & 3980 & -0.0505 & 0.0196 & 0.0100 \\
\hline EUROSPAN & UBE2J1 & rs1062108 & 90132078 & $C / T(T)$ & 0.42 & 3996 & -0.0435 & 0.0198 & 0.0280 \\
\hline POPGEN & GABRR2 & rs9362633 & 90058261 & $\mathrm{~A} / \mathrm{G}(\mathrm{G})$ & 0.05 & 1136 & -0.2430 & 0.0795 & $2.2 \times 10^{-3}$ \\
\hline POPGEN & GABRR2 & rs7764923 & 90079640 & $C / T(T)$ & 0.23 & 1140 & -0.1144 & 0.0387 & $3.1 \times 10^{-3}$ \\
\hline POPGEN & GABRR2 & rs2236204 & 90081831 & $G / T(T)$ & 0.17 & 1121 & -0.1190 & 0.0436 & $6.4 \times 10^{-3}$ \\
\hline POPGEN & Intergenic & rs10944443 & 90087709 & $C / G(C)$ & 0.15 & 1113 & -0.1203 & 0.0469 & 0.0103 \\
\hline POPGEN & Intergenic & rs12195070 & 90090455 & $C / T(T)$ & 0.18 & 1140 & -0.1155 & 0.0430 & $7.2 \times 10^{-3}$ \\
\hline POPGEN & Intergenic & rs12195078 & 90090511 & $C / T(T)$ & 0.15 & 1128 & -0.1261 & 0.0460 & $6.1 \times 10^{-3}$ \\
\hline POPGEN & UBE2J1 & rs9048 & 90094300 & $C / T(T)$ & 0.18 & 1139 & -0.1230 & 0.0417 & $3.1 \times 10^{-3}$ \\
\hline POPGEN & UBE2J1 & rs9351207 & 90115388 & $C / T(T)$ & 0.24 & 1131 & -0.0791 & 0.0387 & 0.0412 \\
\hline
\end{tabular}

\# association models were adjusted for age and sex; *in standard deviations; ${ }^{* *} p$ value: for EUROSPAN, the $p$ value refers to the meta-analysis of the five individual GWA studies, for popgen, the $p$ value is from the linear regression analysis (for details, see Methods).

(UTR), suggesting a regulatory role for this locus. Data on the clones available from public databases clearly show that SYT1 transcription starts around $77,782 \mathrm{~kb}$ and $77,963 \mathrm{~kb}$ on chromosome 12 and that the transcripts are spliced in the 5'UTR region (see, among others, the mRNA clones with GI numbers 37589129, 21753708, 34533586, 34366268, 37589129, 164696663). The synaptotagmins are integral membrane proteins of synaptic vesicles thought to serve as $\mathrm{Ca}(2+)$ sensors in the process of vesicular trafficking and exocytosis [49]. Of particular interest in the present context is expression of the SYT1 gene product, synaptotagmin-I, in renal podocytes. Glomerular podocytes possess structures resembling synaptic vesicles and contain glutamate, they co-express Rab3A (a GTPase restricted to cell types that regulate exocytosis), synapsin, synaptophysin, and synaptotagmin-I, and undergo spontaneous and stimulated exocytosis and recycling, with glutamate release [50]. Synaptotagmin-I plays a role in neurotransmitter release and neurite outgrowth [51] and is thought to interact with neurotransmitters such as the GABA receptors, expressed in the GBM. It also appears to participate in the regulation of podocyte homeostasis [50].

In light of the findings on the $S Y T 1$ gene, the association with the UBE2J1 and GABRR2 locus becomes of high interest. The association detected in the EUROSPAN data was corroborated by the popgen data. Moreover, SNPs associated with $\mathrm{S}_{\mathrm{CR}}$ in popgen enabled us to narrow down the associated region to the GABRR2 promoter. The same locus was not replicated in Korcula data. However, while the popgen genotype distribution of the SNPs in question was found to resemble that of the HapMap-CEU samples [52], indicating that popgen can be considered representative of the general Central to Northern European populations, this may not be true for the Korcula sample. In fact, Korcula is a small population located in the Croatian islands, where pronounced genetic isolation is known to have persisted until recently [53]. This could be the reason of the missed replication. The GABRR2 gene product is a member of the rho subunit family of the transmembrane receptors for gamma-aminobutyric acid $\left(\mathrm{GABA}_{\mathrm{A}}\right)$, which are linked to potassium channels via G-proteins. $\mathrm{GABA}_{\mathrm{A}}$ receptors have been shown to be expressed in the kidney of multiple species, with subunits $\beta_{1}$ and $\beta_{2}$ localized in the proximal tubules [54]. More recently, several subtypes of GABA receptors, including the GABRR2, have been shown to be transcribed in normal human glomeruli [50] and it plays a role in retinal neurotransmission [55]. The gene is located close to the GABRR1 gene in the same transcriptional orientation, suggesting a similar expression and regulatory pattern. Interestingly, the locus falls into the supporting interval for linkage to $S_{C R}$ reported in Mexican Americans [7], and to creatinine clearance as reported in Caucasians [9].

Our discovery analysis was performed in five isolated communities from Southern, Central, and Northern Europe. As has been demonstrated empirically for South Tyrolean villages [56], population isolates provide a reduced within-study heterogeneity of environmental 
factors, thereby facilitating the genetic dissection of complex traits. This internal homogeneity of environmental and life style factors could be counterbalanced by enhanced between-study heterogeneity. However, this appears not to have been the case in our study. For SNPs in 27 of the 29 regions selected for replication, the hypothesis of homogeneity of effects' sizes was not rejected, even at a very stringent significance threshold (given the small number of studies involved in the meta-analysis, $\alpha$ was set to 0.10 ). In particular, homogeneity of association signals was verified for all replicated loci and for the COLAA3 gene locus. This finding strengthens our results in the sense that, despite the expected between-population heterogeneity, the results of the association analyses were found to be very consistent across studies.

Another advantage of our study has been that $\mathrm{S}_{\mathrm{CR}}$ values of all EUROSPAN participants were measured in one and the same centralized laboratory using the enzymatic method. In this way, calibration difference could be excluded as a confounder of our genetic association analyses. While the enzymatic method was used to measure $\mathrm{S}_{\mathrm{CR}}$ in EUROSPAN and popgen participants, the Jaffé rate method was used in the Korcula study. This method is known to be less precise than the enzymatic one. Additional noise introduced by increased measurement error would best explain the reduced evidence for association replication in the Korcula study. However, $\mathrm{S}_{\mathrm{CR}}$ was standardized in all discovery and replication samples using a transformation based upon the ranks of a standard normal distribution. The standardization of the phenotype measures allowed us to combine data across studies avoiding bias due to technical interlaboratory differences.

The validity of our analysis was also evidenced by the replication of earlier association findings [18]. Association of $\mathrm{S}_{\mathrm{CR}}$ with $U M O D$ and SPATA5L1-GATM was confirmed using the same replication approach used in our own analysis. With our method, however, we could not replicate the association over the SCHROOM3 locus (the locus would be confirmed if using a classic replication based on the specific SNP or a proxy SNP). This finding could be an indication that our method of replication is more likely to be conservative and, so, less prone to false positive results. In the COL22A1 and the SYT1 genes the replicated signals were located in different LD blocks, highlighting the possibility that different polymorphisms at the same locus may be associated with the same phenotype in different populations. In the GABRR2 - UBE2J1 gene locus, association signals between discovery and replication studies were discordant but clearly overlapping. Whether the discordance of the effect alleles is an indication of a false positive result is very unlikely, given the size of the effects in
EUROSPAN and in popgen. The presence of a flip-flop phenomenon [57] could be hypothesized and should be investigated further.

\section{Conclusions}

In conclusion, in addition to confirming earlier findings, our search for genes associated with $\mathrm{S}_{\mathrm{CR}}$ variation led to the discovery of three novel genes that represent sensible candidates for further functional analysis. The recent hypothesis of an important role of neurotransmitters in the regulation of the GBM at the podocyte level [50] renders our findings particularly relevant for understanding the regulation of renal function, suggesting that the possible interaction between SYT1 and GABRR2 warrants further investigation.

Additional file 1: Supplementary materials. The file contains supplementary tables to support the discovery analysis (Table S1), the replication analysis (Table S2) and the confirmation of previous findings (Table S3).

Click here for file

[ http://www.biomedcentral.com/content/supplementary/1471-2350-1141-S1.DOC]

\section{Acknowledgements}

We owe a debt of gratitude to all participants in the seven studies and their relatives. We are grateful to Prof. John Thompson for the very constructive discussion on statistical methodology.

EUROSPAN (European Special Populations Research Network) was supported by European Commission FP6 STRP grant number 018947 (LSHG-CT-200601947). High-throughput genome-wide association analysis of the data was supported by joint grant from Netherlands Organization for Scientific Research and the Russian Foundation for Basic Research (NWO-RFBR 047.017.043)

The ERF study was supported by grants from the NWO, Erasmus MC and the Centre for Medical Systems Biology (CMSB). We are grateful general practitioners and neurologists for their contributions and to P. Veraart for her help in genealogy, Jeannette Vergeer for the supervision of the laboratory work and P. Snijders for his help in data collection.

For the MICROS study, we thank the primary care practitioners Raffaela Stocker, Stefan Waldner, Toni Pizzecco, Josef Plangger, Ugo Marcadent and the personnel of the Hospital of Silandro (Department of Laboratory Medicine) for their participation and collaboration in the research project. In South Tyrol, the study was supported by the Ministry of Health and Department of Educational Assistance, University and Research of the Autonomous Province of Bolzano and the South Tyrolean Sparkasse Foundation.

The Northern Swedish Population Health Study was supported by grants from The Swedish Natural Sciences Research Council, The European Commission through EUROSPAN, The Foundation for Strategic Research (SSF) and The Linneaus Centre for Bioinformatics (LCB). We are also grateful for the contribution of samples from the Medical Biobank in Umeå and for the contribution of the district nurse Svea Hennix in the Karesuando study. ORCADES was supported by the Scottish Executive Health Department and the Royal Society. DNA extractions were performed at the Wellcome Trust Clinical Research Facility in Edinburgh. We would like to acknowledge the invaluable contributions of Lorraine Anderson, the research nurses in Orkney, and the administrative team in Edinburgh.

The VIS study was supported through the grants from the Medical Research Council UK to HC, AFW and IR; and Ministry of Science, Education and Sport of the Republic of Croatia to IR (number 108-1080315-0302). The authors collectively thank a large number of individuals for their individual help in organizing, planning and carrying out the field work related to the project 
and data management: Professor Pavao Rudan and the staff of the Institute for Anthropological Research in Zagreb, Croatia (organization of the field work, anthropometric and physiological measurements, and DNA extraction); Professor Ariana Vorko-Jovic and the staff and medical students of the Andrija Stampar School of Public Health of the Faculty of Medicine, University of Zagreb, Croatia (questionnaires, genealogy reconstruction and data entry); Dr Branka Salzer from the biochemistry lab "Salzer", Croatia (measurements of biochemical traits); local general practitioners and nurses (recruitment and communication with the study population); and the employees of several other Croatian institutions who participated in the field work, including but not limited to the University of Rijeka and Split, Croatia; Croatian Institute of Public Health; Institutes of Public Health in Split and Dubrovnik, Croatia. SNP Genotyping of the Vis samples was carried out by the Genetics Core Laboratory at the Wellcome Trust Clinical Research Facility, WGH, Edinburgh.

The popgen study was supported by the German Ministry of Education and Research (BMBF) through the National Genome Research Network (NGFN). It is currently funded by the Ministry of Science, Commerce and Transportation of the State of Schleswig-Holstein. The project has also received infrastructure support through the DFG excellence cluster "Inflammation at Interfaces".

\section{Author details}

${ }^{1}$ Institute of Genetic Medicine, European Academy Bozen/Bolzano (EURAC), Bolzano, Italy - Affiliated Institute of the University Lübeck, Lübeck, Germany. ${ }^{2}$ MRC Human Genetics Unit, Institute of Genetics and Molecular Medicine, Edinburgh, UK. Institute for Clinical Molecular Biology, Christian-AlbrechtsUniversity Kiel, Kiel, Germany. ${ }^{4}$ Genetic Epidemiology Unit, Departments of Epidemiology and Clinical Genetics, Erasmus MC, 3000 CA Rotterdam, the Netherlands. ${ }^{5}$ Department of Genetics and Pathology, Rudbeck laboratory, Uppsala University, SE-751 85, Uppsala, Sweden. ${ }^{6}$ Centre for Population Health Sciences, University of Edinburgh Medical School, Teviot Place, Edinburgh EH8 9AG, UK. ${ }^{7}$ Andrija Stampar School of Public Health, University of Zagreb Medical School, Rockefellerova 4, 10000 Zagreb, Croatia. ${ }^{8}$ Gen-info Ltd, Ruzmarinka 17, 10000 Zagreb, Croatia. ${ }^{9}$ Popgen biobank, ChristianAlbrechts-University Kiel, Kiel, Germany. ${ }^{10}$ Institute for Experimental Medicine, Christian-Albrechts University Kiel, 24105 Kiel, Germany. ${ }^{11}$ Croatian Centre for Global Health, University of Split Medical School, Soltanska 2, 21000 Split, Croatia. ${ }^{12}$ Institute for Clinical Chemistry and Laboratory Medicine, Regensburg University Medical Center, D-93053 Regensburg, Germany. ${ }^{13}$ Institute of Human Genetics, Technical University of Munich, Munich, Germany. ${ }^{14}$ Institute of Human Genetics, Helmholtz Zentrum München, German Research Center for Environmental Health $(\mathrm{GmbH})$, Ingolstaedter Landstr 1, D-85764 Neuherberg, Germany. ${ }^{15}$ Hemodialysis Unit, Hospital of Merano, Merano, Italy. ${ }^{16}$ Institute of Medical Informatics and Statistics, Christian-Albrechts-University, Kiel, Germany. ${ }^{17}$ Department of Neurology, University of Lübeck, Lübeck, Germany. ${ }^{18}$ Department of Neurology, Central Hospital, Bolzano, Italy.

\section{Authors' contributions}

SHW, OP, UN, SS, NH, TM, BO, AFW, HC, CMvD, UG, JFW, MK, IR, and PPP conceived and designed the studies. CP, W, CH, YSA, AJ, Al, DE, and AF performed the data analysis. CP, ADG, SAM, PR, CM, and MK discussed and provided interpretation of the results. $C P, A D G, W, A F, S H W, I K, L Z, T Z, C G$, $\mathrm{SS}, \mathrm{SC}, \mathrm{MB}, \mathrm{PR}, \mathrm{CM}, \mathrm{HC}, \mathrm{UG}$, and MK wrote and revised the manuscript. All authors gave final approval of the manuscript to be published.

\section{Competing interests}

The authors declare that they have no competing interests. The funders had no role in the study design, the data collection and analysis, the decision to publish, or the preparation of the manuscript.

Received: 30 September 2009 Accepted: 11 March 2010 Published: 11 March 2010

\section{References}

1. Stevens LA, Coresh J, Greene T, Levey AS: Assessing kidney functionmeasured and estimated glomerular filtration rate. N Engl J Med 2006, 354(23):2473-2483.

2. Praught ML, Shlipak MG: Are small changes in serum creatinine an important risk factor? Curr Opin Nephrol Hypertens 2005, 14(3):265-270.
3. Whitfield JB, Martin NG: The effects of inheritance on constituents of plasma: a twin study on some biochemical variables. Ann Clin Biochem 1984, 21(3):176-183.

4. Pattaro C, Aulchenko YS, Isaacs A, Vitart V, Hayward C, Franklin CS, Polasek O, Kolcic I, Biloglav Z, Campbell S, Hastie N, Lauc G, Meitinger T, Oostra BA, Gyllensten U, Wilson JF, Pichler I, Hicks AA, Campbell H, Wright AF, Rudan I, van Duijn CM, Riegler P, Marroni F, Pramstaller PP: Genome-wide linkage analysis of serum creatinine in three isolated European populations. Kidney Int 2009, 76(3):297-306.

5. Fox CS, Yang Q, Cupples LA, Guo CY, Larson MG, Leip EP, Wilson PW, Levy D: Genomewide linkage analysis to serum creatinine, GFR, and creatinine clearance in a community-based population: the Framingham Heart Study. J Am Soc Nephrol 2004, 15(9):2457-2461.

6. Hunt SC, Coon H, Hasstedt SJ, Cawthon RM, Camp NJ, Wu LL, Hopkins PN: Linkage of serum creatinine and glomerular filtration rate to chromosome 2 in Utah pedigrees. Am J Hypertens 2004, 17(6):511-515,

7. Arar NH, Voruganti VS, Nath SD, Thameem F, Bauer R, Cole SA, Blangero J, MacCluer JW, Comuzzie AG, Abboud HE: A genome-wide search for linkage to chronic kidney disease in a community-based sample: the SAFHS. Nephrol Dial Transplant 2008, 23(10):3184-3191.

8. Chen G, Adeyemo AA, Zhou J, Chen Y, Doumatey A, Lashley K, Huang H, Amoah A, Agyenim-Boateng K, Eghan BA Jr, Okafor G, Acheampong J, Oli J, Fasanmade O, Johnson T, Rotimi C: A genome-wide search for linkage to renal function phenotypes in West Africans with type 2 diabetes. Am J Kidney Dis 2007, 49(3):394-400.

9. DeWan AT, Arnett DK, Atwood LD, Province MA, Lewis CE, Hunt SC, Eckfeldt J: A genome scan for renal function among hypertensives: the HyperGEN study. Am J Hum Genet 2001, 68(1):136-144.

10. Leon JM, Freedman BI, Miller MB, North KE, Hunt SC, Eckfeldt JH, Lewis CE, Kraja AT, Djousse L, Arnett DK: Genome scan of glomerular filtration rate and albuminuria: the HyperGEN study. Nephrol Dial Transplant 2007, 22(3):763-771.

11. Mottl AK, Vupputuri S, Cole SA, Almasy L, Goring HH, Diego VP, Laston S, Franceschini N, Shara NM, Lee ET, Best LG, Fabsitz RR, MacCluer JW, Umans JG, North KE: Linkage analysis of glomerular filtration rate in American Indians. Kidney Int 2008, 74(9):1185-1191.

12. Placha G, Poznik GD, Dunn J, Smiles A, Krolewski B, Glew T, Puppala S, Schneider J, Rogus JJ, Rich SS, Duggirala R, Warram JH, Krolewski AS: A genome-wide linkage scan for genes controlling variation in renal function estimated by serum cystatin C levels in extended families with type 2 diabetes. Diabetes 2006, 55(12):3358-3365.

13. Puppala S, Arya R, Thameem F, Arar NH, Bhandari K, Lehman DM, Schneider J, Fowler S, Farook VS, Diego VP, Almasy L, Blangero J, Stern MP, Duggirala R, Abboud HE: Genotype by diabetes interaction effects on the detection of linkage of glomerular filtration rate to a region on chromosome 2q in Mexican Americans. Diabetes 2007, 56(11):2818-2828.

14. Schelling JR, Abboud HE, Nicholas SB, Pahl MV, Sedor JR, Adler SG, Arar NH, Bowden DW, Elston RC, Freedman Bl, Goddard KA, Guo X, Hanson RL, Ipp E, lyengar SK, Jun G, Kao WH, Kasinath BS, Kimmel PL, Klag MJ, Knowler WC, Nelson RG, Parekh RS, Quade SR, Rich SS, Saad MF, Scavini M, Smith MW, Taylor K, Winkler CA, et al: Genome-wide scan for estimated glomerular filtration rate in multi-ethnic diabetic populations: the Family Investigation of Nephropathy and Diabetes (FIND). Diabetes 2008, 57(1):235-243.

15. Turner ST, Kardia SL, Mosley TH, Rule AD, Boerwinkle E, de Andrade M: Influence of genomic loci on measures of chronic kidney disease in hypertensive sibships. J Am Soc Nephrol 2006, 17(7):2048-2055.

16. Hwang SJ, Yang Q, Meigs JB, Pearce EN, Fox CS: A genome-wide association for kidney function and endocrine-related traits in the NHLBI's Framingham Heart Study. BMC Med Genet 2007, 8(Suppl 1):S10.

17. Kottgen A, Kao WH, Hwang SJ, Boerwinkle E, Yang Q, Levy D, Benjamin EJ, Larson MG, Astor BC, Coresh J, Fox CS: Genome-wide association study for renal traits in the Framingham Heart and Atherosclerosis Risk in Communities Studies. BMC Med Genet 2008, 9:49.

18. Kottgen A, Glazer NL, Dehghan A, Hwang SJ, Katz R, Li M, Yang Q, Gudnason V, Launer LJ, Harris TB, Smith AV, Arking DE, Astor BC, Boerwinkle E, Ehret GB, Ruczinski I, Scharpf RB, Ida Chen YD, de Boer $\mathbb{H}_{\text {, }}$ Haritunians T, Lumley T, Sarnak M, Siscovick D, Benjamin EJ, Levy D, Upadhyay A, Aulchenko YS, Hofman A, Rivadeneira F, Uitterlinden AG, et al: Multiple loci associated with indices of renal function and chronic kidney disease. Nat Genet 2009, 41:712-717. 
19. Kao WH, Klag MJ, Meoni LA, Reich D, Berthier-Schaad Y, Li M, Coresh J, Patterson N, Tandon A, Powe NR, Fink NE, Sadler JH, Weir MR, Abboud HE, Adler SG, Divers J, lyengar SK, Freedman Bl, Kimmel PL, Knowler WC, Kohn OF, Kramp K, Leehey DJ, Nicholas SB, Pahl MV, Schelling JR, Sedor JR, Thornley-Brown D, Winkler CA, Smith MW, et al: MYH9 is associated with nondiabetic end-stage renal disease in African Americans. Nat Genet 2008, 40(10):1185-1192.

20. Freedman Bl, Hicks PJ, Bostrom MA, Cunningham ME, Liu Y, Divers J, Kopp JB, Winkler CA, Nelson GW, Langefeld CD, Bowden DW: Polymorphisms in the non-muscle myosin heavy chain 9 gene (MYH9) are strongly associated with end-stage renal disease historically attributed to hypertension in African Americans. Kidney Int 2009, 75(7):736-745.

21. Kopp JB, Smith MW, Nelson GW, Johnson RC, Freedman BI, Bowden DW, Oleksyk T, McKenzie LM, Kajiyama H, Ahuja TS, Berns JS, Briggs W, Cho ME, Dart RA, Kimmel PL, Korbet SM, Michel DM, Mokrzycki MH, Schelling JR, Simon E, Trachtman H, Vlahov D, Winkler CA: MYH9 is a major-effect risk gene for focal segmental glomerulosclerosis. Nat Genet 2008, 40(10):1175-1184.

22. Neel J: Minority Populations as Genetic Isolates: The Interpretation of Inbreeding Results. Minority Populations Houndmills, Basingstoke, Hampshire and London: The MacMillan PressBittles AH, Roberts DF 1992, $1-13$.

23. Aulchenko YS, Heutink P, Mackay I, Bertoli-Avella AM, Pullen J, Vaessen N, Rademaker TA, Sandkuijl LA, Cardon L, Oostra B, van Duijn CM: Linkage disequilibrium in young genetically isolated Dutch population. Eur J Hum Genet 2004, 12(7):527-534.

24. Pardo LM, Mackay I, Oostra B, van Duijn CM, Aulchenko YS: The effect of genetic drift in a young genetically isolated population. Ann Hum Genet 2005, 69(3):288-295.

25. Service S, DeYoung J, Karayiorgou M, Roos JL, Pretorious H, Bedoya G, Ospina J, Ruiz-Linares A, Macedo A, Palha JA, Heutink P, Aulchenko Y, Oostra B, van Duijn C, Jarvelin MR, Varilo T, Peddle L, Rahman P, Piras G, Monne M, Murray S, Galver L, Peltonen L, Sabatti C, Collins A, Freimer N: Magnitude and distribution of linkage disequilibrium in population isolates and implications for genome-wide association studies. Nat Genet 2006, 38(5):556-560.

26. Pattaro C, Marroni F, Riegler A, Mascalzoni D, Pichler I, Volpato CB, Dal Cero U, De Grandi A, Egger C, Eisendle A, Fuchsberger C, Gogele M, Pedrotti S, Pinggera GK, Stefanov SA, Vogl FD, Wiedermann CJ, Meitinger T, Pramstaller PP: The genetic study of three population microisolates in South Tyrol (MICROS): study design and epidemiological perspectives. BMC Med Genet 2007, 8:29.

27. Johansson A, Vavruch-Nilsson V, Cox DR, Frazer KA, Gyllensten U: Evaluation of the SNP tagging approach in an independent population sample-array-based SNP discovery in Sami. Hum Genet 2007, 122(2):141-150.

28. Johansson A, Vavruch-Nilsson V, Edin-Liljegren A, Sjolander P, Gyllensten U: Linkage disequilibrium between microsatellite markers in the Swedish Sami relative to a worldwide selection of populations. Hum Genet 2005, 116(1-2):105-113.

29. McQuillan $\mathrm{R}$, Leutenegger $A L$, Abdel-Rahman R, Franklin CS, Pericic M, Barac-Lauc L, Smolej-Narancic N, Janicijevic B, Polasek O, Tenesa A, Macleod AK, Farrington SM, Rudan P, Hayward C, Vitart V, Rudan I, Wild SH, Dunlop MG, Wright AF, Campbell H, Wilson JF: Runs of homozygosity in European populations. Am J Hum Genet 2008, 83(3):359-372.

30. Rudan I, Biloglav Z, Vorko-Jovic A, Kujundzic-Tiljak M, Stevanovic R, Ropac D, Puntaric D, Cucevic B, Salzer B, Campbell H: Effects of inbreeding, endogamy, genetic admixture, and outbreeding on human health: a (1001 Dalmatians) study. Croat Med J 2006, 47(4):601-610.

31. Rudan I, Campbell H, Rudan P: Genetic epidemiological studies of eastern Adriatic Island isolates, Croatia: objective and strategies. Coll Antropol 1999, 23(2):531-546.

32. Guder WG, Hoffmann GE, Hubbuch A, Poppe WA, Siedel J, Price CP: Multicentre evaluation of an enzymatic method for creatinine determination using a sensitive colour reagent. J Clin Chem Clin Biochem 1986, 24(11):889-902.

33. Krawczak M, Nikolaus S, von Eberstein H, Croucher PJ, El Mokhtari NE, Schreiber S: PopGen: population-based recruitment of patients and controls for the analysis of complex genotype-phenotype relationships. Community Genet 2006, 9(1):55-61.
34. Polasek O, Marusic A, Rotim K, Hayward C, Vitart V, Huffman J, Campbell S, Jankovic S, Boban M, Biloglav Z, Kolcic I, Krzelj V, Terzic J, Matec L, Tometic G, Nonkovic D, Nincevic J, Pehlic M, Zedelj J, Velagic V, Juricic D, Kirac I, Belak Kovacevic S, Wright AF, Campbell H, Rudan I: Genome-wide association study of anthropometric traits in Korcula Island, Croatia. Croat Med J 2009, 50(1):7-16.

35. Amin N, van Duijn CM, Aulchenko YS: A genomic background based method for association analysis in related individuals. PLoS One 2007, 2(12):e1274.

36. Chen WM, Abecasis GR: Family-based association tests for genomewide association scans. Am J Hum Genet 2007, 81(5):913-926.

37. Aulchenko YS, Ripke $S$, Isaacs A, van Duijn CM: GenABEL: an R library for genome-wide association analysis. Bioinformatics 2007, 23(10):1294-1296.

38. Higgins JP, Thompson SG, Deeks JJ, Altman DG: Measuring inconsistency in meta-analyses. BMJ 2003, 327(7414):557-560.

39. Purcell S, Neale B, Todd-Brown K, Thomas L, Ferreira MA, Bender D, Maller J, Sklar P, de Bakker PI, Daly MJ, Sham PC: PLINK: a tool set for wholegenome association and population-based linkage analyses. Am J Hum Genet 2007, 81(3):559-575.

40. Fisher R: Statistical methods for research workers. Edinburgh: Oliver and Boyd, 41932.

41. Benjamini $Y$, Hochberg $Y$ : Controlling the false discovery rate: a practical and powerful approach to multiple testing. Journal of the Royal Statistical Society, Series B (Methodological) 1995, 57(1):289-300.

42. Gabriel SB, Schaffner SF, Nguyen H, Moore JM, Roy J, Blumenstiel B, Higgins J, DeFelice M, Lochner A, Faggart M, Liu-Cordero SN, Rotimi C, Adeyemo A, Cooper R, Ward R, Lander ES, Daly MJ, Altshuler D: The structure of haplotype blocks in the human genome. Science 2002, 296(5576):2225-2229.

43. R Development Core Team: R: A Language and Environment for Statistical Computing. 2.8.0 edn. Vienna, Austria: R Foundation for Statistical Computing 2008.

44. Devlin B, Roeder K: Genomic control for association studies. Biometrics 1999, 55(4):997-1004

45. Hudson BG, Tryggvason K, Sundaramoorthy M, Neilson EG: Alport's syndrome, Goodpasture's syndrome, and type IV collagen. N Engl J Med 2003, 348(25):2543-2556.

46. Badenas C, Praga M, Tazon B, Heidet L, Arrondel C, Armengol A, Andres A, Morales E, Camacho JA, Lens X, Davila S, Mila M, Antignac C, Darnell A, Torra R: Mutations in theCOL4A4 and COL4A3 genes cause familial benign hematuria. J Am Soc Nephrol 2002, 13(5):1248-1254.

47. Greene CS, Penrod NM, Williams SM, Moore JH: Failure to replicate a genetic association may provide important clues about genetic architecture. PLoS One 2009, 4(6):e5639.

48. Koch M, Schulze J, Hansen U, Ashwodt T, Keene DR, Brunken WJ, Burgeson RE, Bruckner $P$, Bruckner-Tuderman $L$ : A novel marker of tissue junctions, collagen XXII. J Biol Chem 2004, 279(21):22514-22521.

49. Tokuoka H, Goda Y: Synaptotagmin in Ca2+ -dependent exocytosis: dynamic action in a flash. Neuron 2003, 38(4):521-524.

50. Rastaldi MP, Armelloni S, Berra S, Calvaresi N, Corbelli A, Giardino LA, Li M, Wang GQ, Fornasieri A, Villa A, Heikkila E, Soliymani R, Boucherot A, Cohen CD, Kretzler M, Nitsche A, Ripamonti M, Malgaroli A, Pesaresi M, Forloni GL, Schlondorff D, Holthofer H, D'Amico G: Glomerular podocytes contain neuron-like functional synaptic vesicles. Faseb J 2006, 20(7):976-978.

51. Mikoshiba K, Fukuda M, Ibata K, Kabayama H, Mizutani A: Role of synaptotagmin, a $\mathrm{Ca} 2+$ and inositol polyphosphate binding protein, in neurotransmitter release and neurite outgrowth. Chem Phys Lipids 1999, 98(1-2):59-67.

52. Nothnagel M, Ellinghaus D, Schreiber S, Krawczak M, Franke A: A comprehensive evaluation of SNP genotype imputation. Hum Genet 2009, 125(2):163-171.

53. Vitart V, Biloglav Z, Hayward C, Janicijevic B, Smolej-Narancic N, Barac L, Pericic M, Klaric IM, Skaric-Juric T, Barbalic M, Polasek O, Kolcic I, Carothers A, Rudan P, Hastie N, Wright A, Campbell H, Rudan I: 3000 years of solitude: extreme differentiation in the island isolates of Dalmatia, Croatia. Eur J Hum Genet 2006, 14(4):478-487.

54. Sarang SS, Plotkin MD, Gullans SR, Cummings BS, Grant DF, Schnellmann RG: Identification of the gamma-aminobutyric acid receptor beta(2) and beta(3) subunits in rat, rabbit, and human kidneys. J Am Soc Nephrol 2001, 12(6):1107-1113. 
55. Marcos I, Ruiz A, Blaschak CJ, Borrego S, Cutting GR, Antinolo G: Mutation analysis of GABRR1 and GABRR2 in autosomal recessive retinitis pigmentosa. J Med Genet 2000, 37(6):E5.

56. Marroni F, Grazio D, Pattaro C, Devoto M, Pramstaller P: Estimates of genetic and environmental contribution to 43 quantitative traits support sharing of a homogeneous environment in an isolated population from South Tyrol, Italy. Hum Hered 2008, 65(3):175-182.

57. Lin PI, Vance JM, Pericak-Vance MA, Martin ER: No gene is an island: the flip-flop phenomenon. Am J Hum Genet 2007, 80(3):531-538.

58. Levey AS, Coresh J, Greene T, Stevens LA, Zhang YL, Hendriksen S, Kusek JW, Van Lente F: Using standardized serum creatinine values in the modification of diet in renal disease study equation for estimating glomerular filtration rate. Ann Intern Med 2006, 145(4):247-254.

\section{Pre-publication history}

The pre-publication history for this paper can be accessed here:http://www. biomedcentral.com/1471-2350/11/41/prepub

doi:10.1186/1471-2350-11-41

Cite this article as: Pattaro et al:: A meta-analysis of genome-wide data from five European isolates reveals an association of COL22A1, SYT1, and GABRR2 with serum creatinine level. BMC Medical Genetics 2010 $11: 41$.

\section{Submit your next manuscript to BioMed Central and take full advantage of:}

- Convenient online submission

- Thorough peer review

- No space constraints or color figure charges

- Immediate publication on acceptance

- Inclusion in PubMed, CAS, Scopus and Google Scholar

- Research which is freely available for redistribution

Submit your manuscript at www.biomedcentral.com/submit 